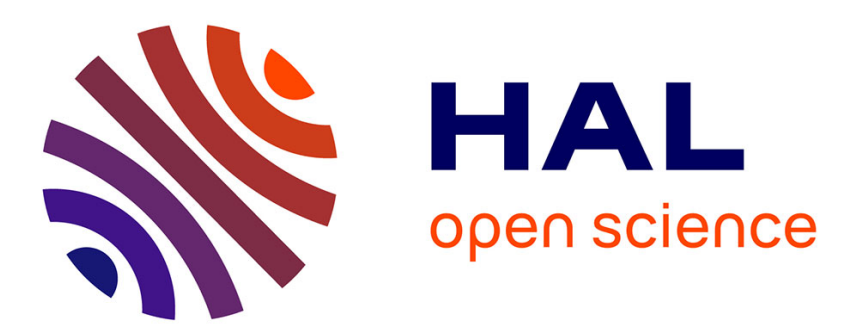

\title{
Cerium/aluminum correlation in aluminosilicate glasses and optical silica fiber preforms
}

Maria Rita Cicconi, Daniel R. Neuville, Wilfried Blanc, Jean-François Lupi, Manuel Vermillac, Dominique de Ligny

\section{To cite this version:}

Maria Rita Cicconi, Daniel R. Neuville, Wilfried Blanc, Jean-François Lupi, Manuel Vermillac, et al.. Cerium/aluminum correlation in aluminosilicate glasses and optical silica fiber preforms. Journal of Non-Crystalline Solids, 2017, 475, pp.85-95. 10.1016/j.jnoncrysol.2017.08.035 . hal-01634893

\section{HAL Id: hal-01634893 https://hal.science/hal-01634893}

Submitted on 14 Nov 2017

HAL is a multi-disciplinary open access archive for the deposit and dissemination of scientific research documents, whether they are published or not. The documents may come from teaching and research institutions in France or abroad, or from public or private research centers.
L'archive ouverte pluridisciplinaire HAL, est destinée au dépôt et à la diffusion de documents scientifiques de niveau recherche, publiés ou non, émanant des établissements d'enseignement et de recherche français ou étrangers, des laboratoires publics ou privés. 


\title{
Cerium/aluminum correlation in aluminosilicate glasses and optical silica fiber preforms
}

\author{
Maria Rita Cicconi ${ }^{a, *}$, Daniel R. Neuville ${ }^{b}$, Wilfried Blanc ${ }^{c}$, Jean-Francois Lupi ${ }^{\mathrm{c}}$, \\ Manuel Vermillac ${ }^{c}$, Dominique de Ligny ${ }^{a}$ \\ ${ }^{a}$ Department Werkstoffwissenschaften, Lehrstuhl für Glas und Keramik, Universität Erlangen-Nürnberg. Martensstrasse 5, D-91058, Erlangen, Germany \\ b Institut de Physique du Globe de Paris, CNRS, Géomatériaux, Sorbonne Paris Cité, 1, rue Jussieu, F-75238 Paris, France \\ ' Université Cóte d'Azur, CNRS, Institut de Physique de Nice, UMR 7010, Parc Valrose, Nice, Cedex 2, France
}

\section{A R T I C L E I N F O}

\section{Keywords:}

XAS

Raman

Photoluminescence

Optical basicity

Optical properties

\begin{abstract}
A B S T R A C T
Optical, structural properties and redox were studied for Ce-bearing silicate and aluminosilicate glasses and Ceactivated silica $\left(\mathrm{SiO}_{2}\right)$ fiber preforms, by X-ray Absorption, Raman and Photoluminescence Spectroscopy.

The introduction of $\mathrm{Al}_{2} \mathrm{O}_{3}$ in Ce-bearing silicate glass strongly stabilizes reduced species in agreement with the optical basicity concept and additionally induces modifications in the $\mathrm{Ce}^{3+}$ surrounding. In $\mathrm{Al}$-free silica preforms, depending on the collapsing conditions, the $\mathrm{Ce}^{3+} / \Sigma \mathrm{Ce}$ ratio has the highest variability $\left(\mathrm{Ce}^{3+} /\right.$ $\Sigma \mathrm{Ce}=0.7-0.85 \pm 0.07$ ), whereas in Al-bearing fiber preforms, Al codoping induces a strong stabilization of $\mathrm{Ce}^{3+}$ species, despite the collapsing atmosphere.

$\mathrm{Al}$ presence induces modifications on Ce local environment, and thus variations of the distance between $\mathrm{Ce}^{3+}$ and its ligands, and/or to variations of the covalency of the bonds. Absorption bands in the UV region, ascribed to Charge-transfer (CT) bands, in our samples, occur only for low amount of $\mathrm{Ce}^{4+}\left(\mathrm{Ce}^{3+} / \Sigma \mathrm{Ce}>0.85 \pm 0.07\right)$. Indeed, in silicate and aluminosilicate glasses the higher amount of $\mathrm{Ce}^{4+}$ does not give rise to UV absorption bands ascribed to CT processes, whereas, in fiber preforms, $\mathrm{Ce}^{3+}$ species can induce the trapping of hole centers, and enhance the photoluminescence efficiency. More generally, these results enhance our understanding of REE structural and chemical roles in amorphous materials and increase our knowledge for technical applications.
\end{abstract}

\section{Introduction}

Rare-earth elements (REE)-bearing materials are economically and technologically important and they have a strong impact in many fields, including geo- and materials sciences and, especially in the development of high-power laser, solid-state devices, electronic and optical devices, as well as in the ceramic industries [1-5]. To improve these technological applications, it is necessary to increase our understanding of REE structural and chemical roles in amorphous materials. Among REE, $\mathrm{Ce}^{3+}$ has attracted much attention thanks its $5 d \rightarrow 4 f$ emission [6], whereas the presence of $\mathrm{Ce}^{4+}$ is an issue for luminescent applications because this ion does not emit light. Indeed, cerium in glasses may be present both in tri- and tetravalent states, and the proportion between them, as for many other multivalent elements, depends on several factors, including cerium content, oxidizing-reducing conditions during glass synthesis, temperature, and glass bulk chemistry [4,7-10].

Optical absorption and luminescence spectroscopy are widely used lab techniques to investigate REE- and transition elements-bearing glasses, and have been extensively employed to study Ce-doped glasses $[7,8,10-12]$. However, the quantification of Ce redox state in glasses by these spectroscopic techniques is very controversial. Indeed, both Ce species present absorption in the UV-region with an overlap of broad bands, which increases or decreases depending on many factors. $\mathrm{Ce}^{4+}$ does not show luminescence due to closed electronic shell ([Xe] $4 f^{\circ}$ ), whereas trivalent cerium ( $[\mathrm{Xe}] 4 f^{1}$ ) is optically active and has fluorescence emission that originates from a transition from one (or more) of the $5 \mathrm{~d}$ levels, to the $2 \mathrm{~F}$ ground state $[7,13,14] . \mathrm{Ce}^{3+}$ may lose the $4 f$ electron to form $\mathrm{Ce}^{4+}$ by direct ionization or by trapping a hole, $\mathrm{Ce}^{3+}+\mathrm{h}^{+} \rightarrow \mathrm{Ce}^{4+}$, and $\mathrm{Ce}^{4+}$ may trap an electron, $\mathrm{Ce}^{4+}+\mathrm{e}^{-} \rightarrow \mathrm{Ce}^{3+}$, and the charge-transfer (CT) gives rise to a broad absorption band in the UV region (around $4.8 \mathrm{eV}$ ).

Recently, in $\mathrm{Yb}$ or Tm-based glass fibers, the co-doping of $\mathrm{Al}$ and $\mathrm{Ce}$ has been studied, for different host compositions, as an effective way to reduce photodarkening (PD) $[15,16]$. Indeed, PD is mitigated by codoping with $\mathrm{P}$ or $\mathrm{Al}$, or a combination of $\mathrm{Al}, \mathrm{P}$, and $\mathrm{Ce}[15,17,18]$. Shao

\footnotetext{
* Corresponding author.

E-mail address: maria.rita.cicconi@fau.de (M.R. Cicconi).
} 
and coauthors [16] demonstrated that trapped electron centers and trapped hole centers were inhibited by Ce doping, and they suggested that the coexistence of the redox couple $\mathrm{Ce}^{3+} / \mathrm{Ce}^{4+}$ in glasses provides means for trapping both hole- and electron-related color centers. Jetschke et al. [17] have shown that a small portion of $\mathrm{Ce}^{3+}$ ions are temporarily oxidized to $\mathrm{Ce}^{4+}$ by trapping released holes in the pump process, which ensures that the hole related color centers are suppressed. The ability to trap electrons/holes has been the most used explanation to explain the photodarkening mitigation in Yb-activated fibers [15-17], and recently, also in Tm-based fibers [18]. However, the role of $\mathrm{Ce}$, and the redox ratios that favor the suppression of photodarkening have not been clarified. To gain insight into the favored mechanisms, it is necessary to accurately determine the $\mathrm{Ce}^{3+} / \mathrm{Ce}^{4+}$ ratio, and provide insights into the codopant(s) structural role, and on the effect of manufacturing conditions (e.g. collapsing atmosphere). The study of the element speciation in fiber preforms is particularly complex due to the limited dimension of the doped core, and to the low concentration of the dopants.

In order to better quantify the variations occurring in Ce-activated silica fiber preforms codoped with $\mathrm{Al}$, in this study, glasses in the ternary $\mathrm{SiO}_{2}-\mathrm{Na}_{2} \mathrm{O}-\mathrm{Al}_{2} \mathrm{O}_{3}$ system, with constant molar content of $\mathrm{SiO}_{2}$ $(\sim 66.6 \mathrm{~mol} \%)$ and with $\mathrm{Al} /(\mathrm{Al}+\mathrm{Na})$ ratios varying from 0 to 0.54 , have been used to study Ce structural role and redox, depending on $\mathrm{Al}$ presence and content. Data obtained from X-ray absorption spectroscopy (XAS) at the Ce $\mathrm{L}_{\mathrm{II}}$-edge, photoluminescence (PL), and Raman spectroscopy are presented. The sensibility and the resolution achievable with these spectroscopy techniques allowed obtaining reproducible results. Discussions of the outcomes are based on the quantified $\mathrm{Ce}^{3+} / \Sigma \mathrm{Ce}$ ratios, on the structural variations occurring in the glass network, and on the chemistry (optical basicity) of the glasses.

\section{Experimental methods}

The starting material has been prepared from dried pure $\mathrm{Al}_{2} \mathrm{O}_{3}, \mathrm{SiO}_{2}$ and $\mathrm{Na}_{2} \mathrm{CO}_{3}$ in stoichiometric proportions. The mixtures were homogenized in an agate mortar and melted twice in air, at $1400{ }^{\circ} \mathrm{C}$, in order to obtain a homogeneous bubble-free glass. The bulk glasses obtained have compositions corresponding to aluminosilicate glasses in the $\mathrm{SiO}_{2}$ $\mathrm{Na}_{2} \mathrm{O}-\mathrm{Al}_{2} \mathrm{O}_{3}$ system, with constant $\mathrm{SiO}_{2}$ molar content ( $\left.\sim 66.6 \mathrm{~mol} \%\right)$ and $\mathrm{Al} / \mathrm{Na}$ ratios from 0.0 to 1.17. Ce-free glasses are named NA66.y, with $\mathrm{y}=\mathrm{Al}_{2} \mathrm{O}_{3}$ and $\mathrm{Na}_{2} \mathrm{O}=100-(66+\mathrm{y}) .10 \mathrm{~g}$ of each was finely ground, doped with $0.36 \mathrm{~mol}^{2} \mathrm{CeO}_{2}$, then remelted in air. Ce-bearing aluminosilicate glasses are labeled NAC66.y. The glasses obtained were checked by Raman and optical microscope to ensure homogeneity and absence of crystalline phases. Glass compositions and synthesis conditions are listed in Table 1.

Ce-activated silica $\left(\mathrm{SiO}_{2}\right)$ preforms were fabricated by the conventional modified chemical vapor deposition (MCVD) technique [19], and the so-called solution doping technique [20] was applied to incorporate aluminum and REE (cerium and thulium): the pure silica core porous layer was soaked with a solution of water containing chlorides salts of desired concentrations to prepare $\mathrm{Ce}, \mathrm{Ce}-\mathrm{Al}$ and $\mathrm{Ce}-\mathrm{Tm}-\mathrm{Al}$ doped samples. $\mathrm{CeCl}_{3}: 6 \mathrm{H}_{2} \mathrm{O}, \mathrm{TmCl}_{3}: 6 \mathrm{H}_{2} \mathrm{O}$ and $\mathrm{AlCl}_{3}: 6 \mathrm{H}_{2} \mathrm{O}$ concentrations were $0.08,0.02$ and $0.7 \mathrm{~mol} / \mathrm{l}$, respectively. After drying of the solvent, the core layer was sintered down to a dense glass layer in $\mathrm{O}_{2}$, He or $\mathrm{N}_{2}$ flux (except for the first pass which was always made under $\mathrm{O}_{2}$ atmosphere). Then, the tube was collapsed under the same flux into a solid rod, referred to as preform, at an elevated temperature higher than $1800^{\circ} \mathrm{C}$. Ce-activated silica preforms are labeled depending on the dopant/codopant, and on the flux during collapsing $\left(\mathrm{He}, \mathrm{O}_{2}, \mathrm{~N}_{2}\right.$, Table 1). Sections of the preforms were cut and polished to optical quality. The preform discs obtained are $\sim 0.9 \mathrm{~mm}$ in diameter, with the doped cores in the range of $280-400 \mu \mathrm{m}$.

X-ray absorption spectroscopy (XAS) experiments at the Ce LII-edge $(5723 \mathrm{eV})$ were carried out at BM25A beamline (ESRF, France). Ce model compounds $\left(\mathrm{Ce}^{4+} \mathrm{O}_{2}\right.$ and $\mathrm{Ce}^{3+}$-pyrochlore) and powdered glasses were prepared by smearing finely ground powder on a Kapton tape. The flat sample surface was placed $45^{\circ}$ with respect incoming beam and detector. Ce spectra were acquired in fluorescence mode by using a Si 13-elements detector and the energy was calibrated by defining the first derivative peak of a metallic $\mathrm{Cr}$ reference foil $(5989 \mathrm{eV})$ acquired, simultaneously to the samples, in transmission mode. A Si (111) crystal monochromator was used, providing an energy resolution of $\sim 0.8 \mathrm{eV}$ at $5.8 \mathrm{keV}$, but considering the finite core-hole width of Ce at the $\mathrm{L}_{\mathrm{II}}$-edge, the resulting convoluted energy resolution is around $4 \mathrm{eV}$. A few experiments, in order to describe the evolution of Ce XAS spectra depending on the redox, have been done at high temperatures (HT) via Dispersive-XAS (D-XAS). Spectra for a Na-disilicate glass (Na66.00) containing $1.8 \mathrm{~mol} \% \mathrm{CeO}_{2}$ were acquired in transmission mode at ODE beamline (SOLEIL, France). ODE is an energy-dispersive beamline with a $\mathrm{Si}(111)$ bent polychromator crystal at the focal point of which the sample is placed. The beam size was $\sim 30 \times 30 \mu \mathrm{m}$ (FWHM). Due to the fixed energy-position correlation in the diffracted energy band, a complete spectrum was obtained from measurements of the intensity distribution on a position-sensitive detector. For high-temperatures (HT) experiments the samples were loaded as microgrampowders in a $0.5 \mathrm{~mm}$ hole of the Pt-Ir $10 \%$ heating wire of the microfurnace previously used for in situ high-temperature studies of Eu and Fe in silicate glasses i.e. [21-23]. Because a spectrum is recorded in the order of milliseconds, this beamline is particularly well suited to investigate reduction/oxidation kinetics processes at $\mathrm{HT}$. The closed microfurnace allows also the use of different gases $\left(\mathrm{Ar} / \mathrm{H}_{2}, \mathrm{Ar}, \mathrm{O}_{2}\right)$ to obtain different redox environments. For all XAS spectra background was subtracted using a linear function and then normalised for atomic absorption on the average absorption coefficient of the spectral region from 5750 to $5780 \mathrm{eV}$. The threshold energy was taken as the first maximum of the first derivative of the spectra, whereas the main peak positions were obtained by calculating the second derivative of the spectra.

Analyses of optical emission and excitation behaviour (PL) were performed with a spectrofluorometer equipped with double monochromators (Czerny-Turner) in excitation and emission (Fluorolog3, Horiba Jobin Yvon), using a $450 \mathrm{~W}$ Xe-lamp as excitation source. All measurements were carried out with excitation and emission spectral resolution of $1 \mathrm{~nm}$. The photoluminescence measurements for aluminosilicate glasses were carried out on polished glasses with dimension of $\sim 0.8-1.0 \mathrm{~cm}$, whereas for silica preforms discs the cladding portion was masked by a black tape (matt black foil), in order to collect the signal almost exclusively from the doped core. Several measurements were repeated in order to ensure the reproducibility.

Raman spectra have been collected both with laser excitations at $488 \mathrm{~nm}$ and $532 \mathrm{~nm}$ at the Department of Materials Science and Engineering (WW3, FAU Erlangen). The Thermo Scientific Nicolet ${ }^{\mathrm{Tm}}$ Almega Raman spectrometer coupled with a high-quality Olympus visible microscope, and a high resolution grating (2400 lines/mm) provided a very good spatial and frequency resolution, respectively of $\sim 1 \mu \mathrm{m}$ and $1 \mathrm{~cm}^{-1}$.

Aluminosilicate glasses and fiber preforms were analyzed by scanning electron microscopy (SEM) (Merlin ${ }^{\mathrm{TM}}$, Carl Zeiss AG, Germany). The chemical composition was evaluated with an energy dispersive Xray spectrometer (EDS) (X-Max ${ }^{\mathrm{N}}$, Oxford Instruments plc., UK).

\section{Results and discussion}

\subsection{XAS and D-XAS}

Ce crystalline compounds used as trivalent and tetravalent Ce references are, respectively, Ce-pyrochlore and $\mathrm{CeO}_{2}$ [24]. As shown in Fig. 1a trivalent and tetravalent Ce compounds display strong differences in the Ce $\mathrm{L}_{\text {III- }}$-edge X-ray absorption near-edge structure (XANES) region. The $\mathrm{Ce}^{3+}$-pyrochlore has a relatively narrow white-line at $\sim 5727 \mathrm{eV}$ arising from the transition (vertical dashed line $a$ ), whereas 
Table 1

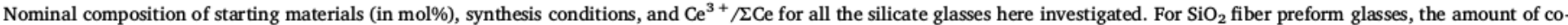
dopant (ppm.at), and the conditions for collapsing are reported.

\begin{tabular}{|c|c|c|c|c|c|c|c|c|c|}
\hline Label/mol\% & $\mathrm{SiO}_{2}$ & $\mathrm{Na}_{2} \mathrm{O}$ & $\mathrm{Al}_{2} \mathrm{O}_{3}$ & $\mathrm{CeO}_{2}$ & $\mathrm{~T}\left({ }^{\circ} \mathrm{C}\right)$ & Atmosphere & $\begin{array}{c}\mathrm{Ce}^{3+} / \Sigma \mathrm{Ce} \\
\pm 0.07\end{array}$ & Theoretical optical basicity $(\Lambda)$ & $\begin{array}{l}\mathrm{Tg}^{\S} \\
(\mathrm{K})\end{array}$ \\
\hline NA66.00 & 66.66 & 33.33 & & & 1300 & Air & - & 0.62 & 726 \\
\hline NAC 66.00 & 66.43 & 33.22 & & 0.36 & 1400 & Air & 0.35 & 0.62 & \\
\hline NA66.01 & 66.66 & 32.33 & 1 & & 1400 & Air & - & 0.61 & \\
\hline NAC 66.01 & 66.43 & 32.22 & 1 & 0.36 & 1400 & Air & 0.37 & 0.61 & \\
\hline NA66.10 & 66.66 & 23.33 & 10 & & 1400 & Air & - & 0.55 & 814 \\
\hline NAC66.10 & 66.42 & 23.24 & 9.96 & 0.36 & 1400 & Air & 0.5 & 0.55 & \\
\hline NA66.18 & 66.66 & 15.33 & 18 & & 1400 & Air & - & 0.51 & 1089 \\
\hline NAC66.18 & 66.4 & 15.27 & 17.93 & 0.36 & 1400 & Air & 0.85 & 0.51 & \\
\hline Label/ppm.at ${ }^{\#}$ & & $\operatorname{Tm}$ & $\mathrm{Al}$ & $\mathrm{Ce}$ & & & & & \\
\hline $\mathrm{Ce}\left(\mathrm{N}_{2}\right)$ & & & & 1300 & * & $\mathrm{N}_{2}$ & - & 0.48 & \\
\hline $\mathrm{CeAl}\left(\mathrm{N}_{2}\right)$ & & & 17,000 & 3800 & $\cdot$ & $\mathrm{N}_{2}$ & 1 & 0.47 & \\
\hline $\mathrm{Ce}\left(\mathrm{O}_{2}\right)$ & & & & 3300 & $\cdot$ & $\mathrm{O}_{2}$ & 0.85 & 0.48 & \\
\hline $\mathrm{CeAl}\left(\mathrm{O}_{2}\right)$ & & & 15,000 & 3500 & . & $\mathrm{O}_{2}$ & 0.9 & 0.47 & \\
\hline $\mathrm{Ce}(\mathrm{He})$ & & & & 3100 & • & $\mathrm{He}$ & 0.7 & 0.48 & \\
\hline $\mathrm{CeAl}(\mathrm{He})$ & & & 17,000 & 3000 & * & $\mathrm{He}$ & 0.9 & 0.47 & \\
\hline CeAl-Tm & & 260 & 8000 & 1300 & $\cdot$ & $\mathrm{O}_{2}$ & $0.85 \pm 0.1$ & 0.47 & \\
\hline
\end{tabular}

Notes:

${ }^{\S}$ From [61].

From [18].

* Estimated from SEM-EDS analyses.

* Prepared by MCVD (see experimental section).

$\mathrm{Ce}^{4+}$ compound $\left(\mathrm{CeO}_{2}\right)$ has other three features, respectively labeled $b$, $c$ and $d$ in Fig. 1a, according to Bianconi et al. [25]. Peak $d$ corresponds to the electronic transition, whereas peak $c$ is due to the transition, where an electron is transferred from ligand (L) orbitals (i.e., $2 p$ of oxygen) to the $4 f$ shell of Ce. The position and the integrated area of peak $c$, relative to peak $d$, is strongly dependent on the Ce chemical environment $[25,26]$. Peak $b$ is assigned to the transition, which is forbidden from the selection rule, $\Delta l= \pm 1$. Hybridization of $5 d-4 f$ orbitals allows the transition to appear as a small peak [25,27]. The different spectra for $\mathrm{Ce}^{3+}$ and $\mathrm{Ce}^{4+}$ can be used as fingerprint for the presence of both species.

In order to evaluate the variations of the $\mathrm{Ce}_{\mathrm{L}_{I I}}$-edge XANES spectra depending on Ce redox ratio we performed in-situ experiments at ODE beamline (SOLEIL, France). Microgram-powder of the starting NAC66.00 glass $\left(1.8 \mathrm{~mol}_{0} \mathrm{CeO}_{2}\right)$ was inserted in the heating wire and heated up to $\sim 1060^{\circ} \mathrm{C}$ (temperatures controlled "in-situ" with a pyrometer: error $\pm 10^{\circ} \mathrm{C}$ ). After completely reducing the melts in $\mathrm{Ar} / \mathrm{H}_{2}$ atmosphere we started to follow the Ce redox kinetic at high temperature under $\mathrm{O}_{2}$ flux. Each spectrum was acquired every $5 \mathrm{~s}$ until the equilibrium was reached (no further changes in the spectra after
15-25 min). The two XANES end-member spectra (fully oxidized and fully reduced) were used for a linear combination (Fig. 1b), and compared to each single spectrum acquired, in order to provide the quantification of the $\mathrm{Ce}^{3+} / \Sigma \mathrm{Ce}$ ratios in all the other spectra/samples. In Fig. 1b is shown the evolution of the Ce XANES spectra with time for the Ce-bearing NA66.00 melt. In addition to the linear combination method, another procedure was done to quantify the $\mathrm{Ce}^{3+} / \Sigma \mathrm{Ce}$ ratios, in order to provide an error relative to the estimation of each Ce species present in the glasses. Following the work of [9], we used the ratio between the maximum intensities (minimum values found by the second derivative) of the peaks relative to $\mathrm{Ce}^{3+}$ (down arrow in Fig. 1b) and $\mathrm{Ce}^{4+}$ (up arrow in Fig. 1b) from the linear combinations, to build a calibration curve. The values from the aluminosilicate glasses fall into the confidence band (95\%) except for the Al-free glass which has a higher scattering. As a result, the error associated to the $\mathrm{Ce}^{3+}$, $\Sigma$ Ce ratio was fixed to \pm 0.07 .

Glasses of Na-aluminosilicate composition, doped with $0.36 \mathrm{~mol} \%$ $\mathrm{CeO}_{2}$, have been studied by X-ray Absorption Spectroscopy (XAS) at room temperature. Normalised spectra for four aluminosilicate glasses are shown in Fig. 2. The XANES spectra are typical of compounds with a

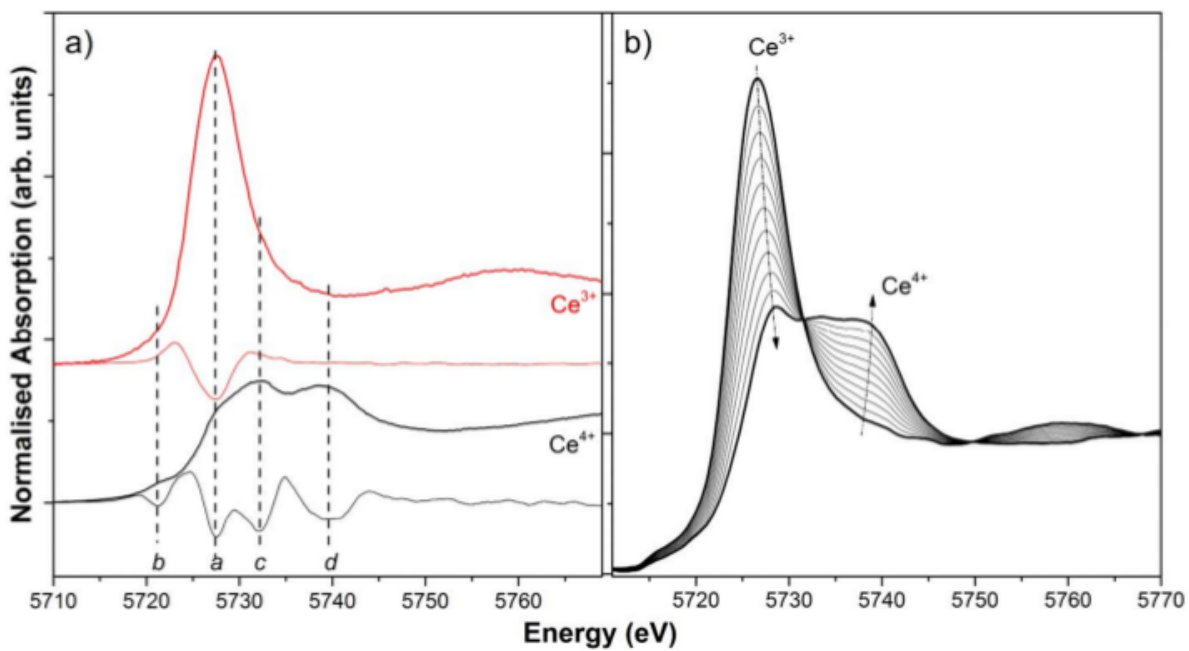

Fig. 1. a): Normalised Ce $\mathrm{L}_{m}$-edge XANES spectra for $\mathrm{Ce}^{3+}$ and $\mathrm{Ce}^{4+}$ reference compounds, along the respective second derivatives. Letters and dotted lines indicate the electronic transitions associated to the different features (see text). b) Linear combination of the two XANES end-members acquired at $\mathrm{HT}$ in-situ. The bold lines represent the fully oxidized $\left(\mathrm{Ce}^{4+}\right)$ and the fully reduced spectra $\left(\mathrm{Ce}^{3+}\right)$. 

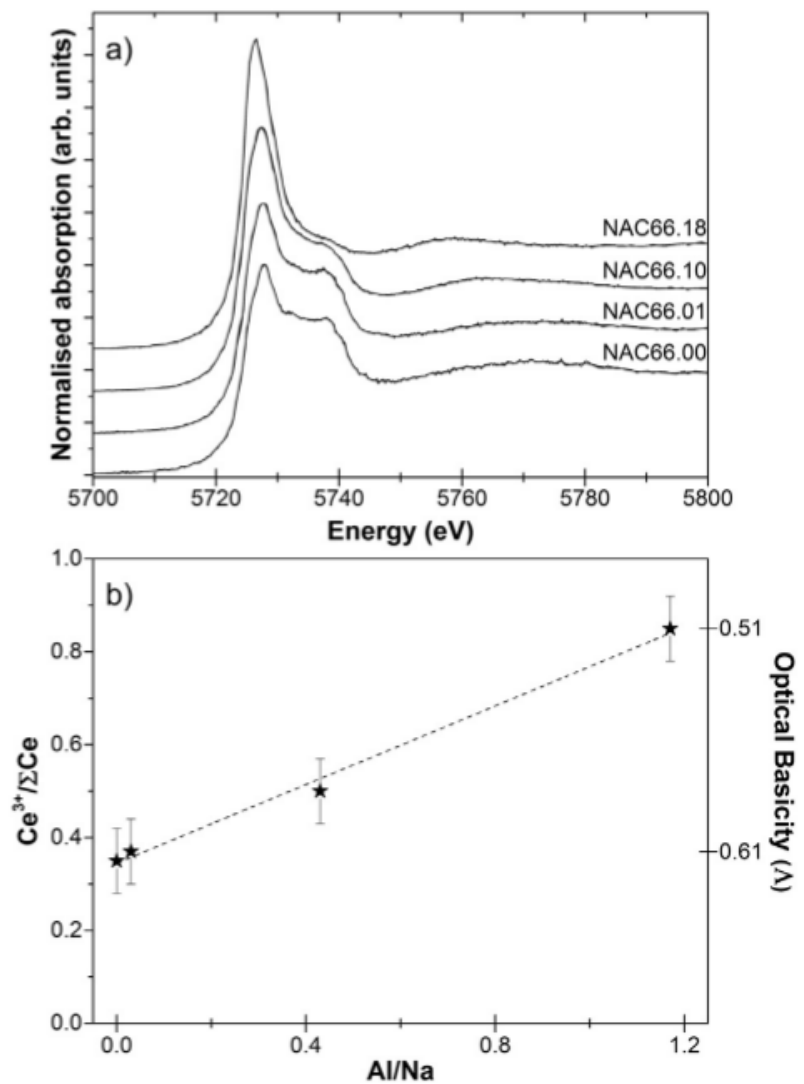

Fig. 2. a) Normalised Ce $\mathrm{L}_{\mathrm{m}}$-edge XANES spectra for Ce-aluminosilicate glasses. b) $\mathrm{Ce}^{3+}$ / $\Sigma \mathrm{Ce}$ redox ratios estimated for the glasses are plotted against their $\mathrm{Al} / \mathrm{Na}$ molar ratio. There is a correlation between $\mathrm{Ce}^{3+} / \Sigma \mathrm{Ce}$ redox ratio and both $\mathrm{Al} / \mathrm{Na}$ molar ratio and theoretical optical basicity $(\Lambda)$.

mixture of the two valences, since both the characteristic features of $\mathrm{Ce}^{3+}$ and $\mathrm{Ce}^{4+}$ are present (Fig. 2). On the other hand, clearly there is a trend and by increasing the amount of $\mathrm{Al}_{2} \mathrm{O}_{3}$ the main peak increases in intensity, whereas the shoulder at higher energy, associated to $\mathrm{Ce}^{4+}$, is decreasing. The $\mathrm{Ce}^{3+} / \Sigma \mathrm{Ce}$ ratio for each glass was obtained by comparing the XANES spectra with those of the linear combination (Table 1), and when plotting the estimated $\mathrm{Ce}^{3+} / \Sigma \mathrm{Ce}$ ratios vs. the $\mathrm{Al} /$ $\mathrm{Na}$ ratio (Fig. 2b), the positive correlation is clear. Indeed, the substitution of $\mathrm{Al}$ for Na stabilizes reduced Ce species in the glasses.

The theoretical optical basicity $(\Lambda)$ values for the glasses here investigated can be used satisfactorily to predict the Ce redox states, in agreement with previous studies [28-30]. By increasing the optical basicity, the content of oxidized species in the glasses increases, and by increasing $\mathrm{Al}$ content there is a decrease of the $\Lambda$ (Fig. 2b).

Ce $\mathrm{L}_{\mathrm{II}}$-edge XANES spectra have been collected also for Ce-activated silica glasses, either $\mathrm{Al}$-free or $\mathrm{Al}$-doped, collapsed under different atmospheres $\left(\mathrm{He}, \mathrm{O}_{2}, \mathrm{~N}_{2}\right.$ ) (Fig. 3). All silica preforms have high $\mathrm{Ce}^{3+} /$ $\Sigma \mathrm{Ce}$ ratios (see Table 1). The collapsing atmosphere, for the Al-free preforms, to some extent, influences the Ce redox ratio (Fig. 3a,b) with the glass prepared in $\mathrm{He}$, unexpectedly, resulting in the highest amount of oxidized species $\left(\mathrm{Ce}^{3+} / \Sigma \mathrm{Ce}=0.7 \pm 0.07\right.$, black line in Fig. 3a). As observed for aluminosilicate glasses, $\mathrm{Al}$ presence in silica preforms induces a strong stabilization of $\mathrm{Ce}^{3+}$ (Fig. 3b) compared to $\mathrm{Ce}^{4+}$, and even the gases used have somehow a subordinate influence with respect to $\mathrm{Al}$ codoping effect. Indeed, the estimated $\mathrm{Ce}^{3+} / \Sigma \mathrm{Ce}$ ratios range between 0.9 and $1( \pm 0.07)$.

In Ce-activated silica preforms, considering the amount of Al doping with respect to the Ce content, and following the trend observed for the Na-aluminosilicate glasses, it can be expected a variation of the $\mathrm{Ce}$ redox ratio up to $35 \%$, depending on the presence or not of $\mathrm{Al}$.

\subsection{Photoluminescence spectroscopy}

Photoluminescence (PL) measurements, in the UV-Vis range, have been done for all the glasses. Both excitation and emission spectra for Ce-bearing compounds largely shift depending on bulk composition, Ce content, temperature, etc.... $([7,10,14]$ and references therein) nevertheless, the optical basicity (OB) [31-33], or the polarizability [34-36] have been used to predict the variations occurring on Ce luminescence properties $[10,37]$.

In Fig. 4, the normalised emission (EM) and excitation (EX) spectra for the set of aluminosilicate glasses are shown. The broad emission band is associated to the allowed electronic transition $5 d \rightarrow 4 f$. The spin-orbit interaction splits the ground level into two sublevels (doublet ${ }^{2} \mathrm{~F}_{5 / 2}$ and ${ }^{2} \mathrm{~F}_{7 / 2}$ ) [14] which causes the strong asymmetricity of the photoluminescence. The emission bands have been analyzed and deconvoluted in two Gaussians [12] and the two components splitting, of around $2200 \mathrm{~cm}^{-1}$, is in agreement with the literature [12,14].

Ce-bearing aluminosilicate glasses (Fig. 4) have luminescence excitation and emission bands at different wavelengths, depending on the presence or the amount of Al. All emission bands are asymmetric and broad, whereas the excitation bands are relatively narrow asymmetrical peaks with a maximum around $346-357 \mathrm{~nm}$, and a shoulder peaking around $300 \mathrm{~nm}$. Samples NAC66.00 and NAC66.01 have almost the same Ce redox and $\mathrm{OB}$ values, however the photoluminescence shows a little shift toward blue (see Table 2) both for emission and excitation bands. These variations can be respectively ascribed to the decrease of the component at higher wavelengths $(\sim 460 \mathrm{~nm})$ in the emission band, and to a slight increase of the shoulder at $\sim 300 \mathrm{~nm}$ in the excitation band, due to $\mathrm{Al}$ presence (arrow in Fig. 4). The prevalent presence of $\mathrm{Ce}^{4+}(>60 \%)$ in these glasses do not cause strong modifications in the UV region.

The strongest differences in the photoluminescence can be observed for the glass with the highest amount of $\mathrm{Al}$ (NAC66.18), with Stokes shifts strongly reduced, and also with lower spin-orbit splitting of the ground $4 f$ level $\left(\sim 1995 \mathrm{~cm}^{-1}\right)$ (Table 2$)$. In this sample, the emission band is largely shifted at lower wavelengths, along with a net increase of the band at $\sim 300 \mathrm{~nm}$ in the excitation spectrum.

Aluminosilicate glasses, following the Al substitution for $\mathrm{Na}$, present a blue shift of both excitation and emission spectra, except for glass NAC66.10, which is out of trend. It represents always the maximum variation, with the highest Stokes shifts $\left(5437.8 \mathrm{~cm}^{-1}\right)$ and the highest splitting of the ground $4 f$ level $\left(\sim 2280 \mathrm{~cm}^{-1}\right)$, and with both emission and excitation bands shifted toward red wavelengths (respectively $\sim 443 \mathrm{~nm}$ and $\sim 357 \mathrm{~nm}$, Fig. 4).

Ce-activated silica preforms (Fig. 5) as well have broad asymmetric emission bands, and there is a clear difference for $\mathrm{Al}$-free and $\mathrm{Al}$ codoped samples. Indeed, Al co-doped preforms, around $400 \mathrm{~nm}$, have an asymmetric emission band, very similar to that of Al-rich silicate glass (NAC66.18), and also with very similar values for the spin-orbit splitting of the ground $4 f$ level $\left(\sim 2000 \mathrm{~cm}^{-1}\right.$, Table 2$)$. On the contrary, Alfree preforms have much broader and red shifted $(\sim 450 \mathrm{~nm})$ emission bands. The deconvolution of the emission bands for the Al-free preforms show that the spin-orbit splitting of the ground $4 f$ level is much higher compared to other glasses and preforms, especially the one collapsed under $\mathrm{N}_{2}\left(\sim 2700 \mathrm{~cm}^{-1}\right.$, Table 2$)$. Thus, the $5 d \rightarrow\left({ }^{2} \mathrm{~F}_{5 / 2}\right.$ and ${ }^{2} \mathrm{~F}_{7 / 2}$ ) splitting by itself, cannot justify the energy difference between the two Gaussian needed for the deconvolution.

The excitation spectra for silica preforms are also broader and show the presence of two components at lower wavelengths (see arrows in Fig. 5). The first one has a similar position to that observed in aluminosilicate glasses $(\sim 300 \mathrm{~nm})$, whereas the second one is at shorter wavelengths $(\sim 275 \mathrm{~nm}$ or $\sim 4.5 \mathrm{eV})$. This latter contribution probably could be related to Charge Transfer (CT) band(s), and it is interesting to observe that by increasing the $\mathrm{Ce}^{3+} / \Sigma \mathrm{Ce}$ ratio in the preforms, this contribution raises. Moreover, contrary to aluminosilicate glasses, the large variations in fiber emission spectra do not go along with the shift 


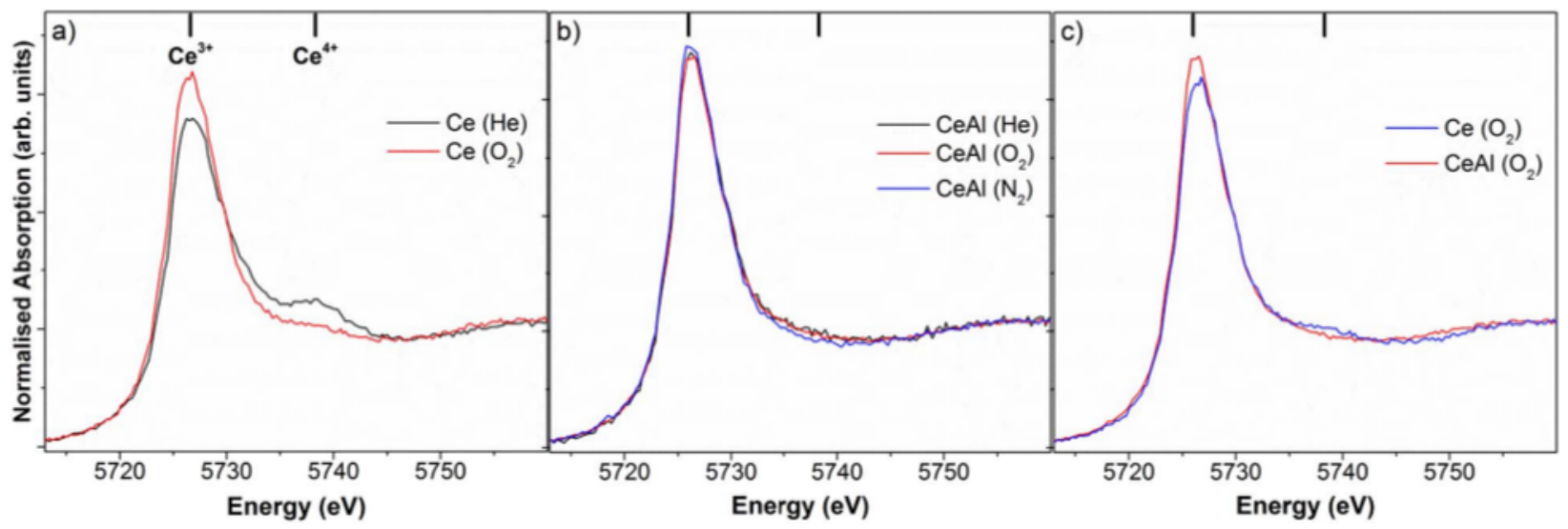

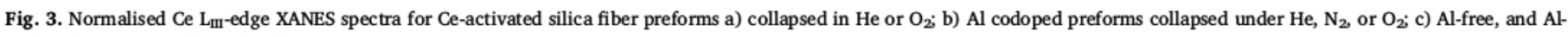
codoped preforms collapsed under $\mathrm{O}_{2}$.

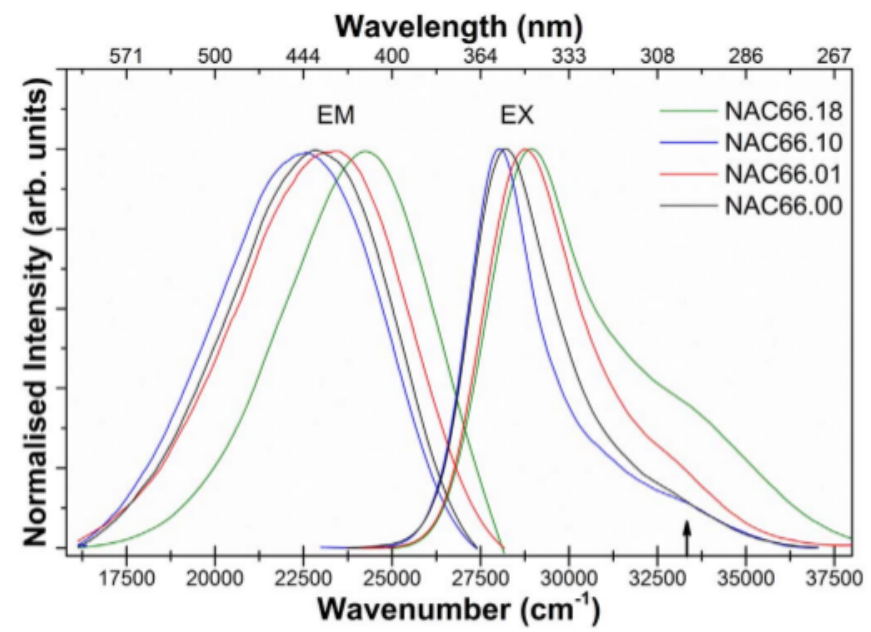

Fig. 4. Excitation (EX) and emission (EM) spectra for Ce-bearing aluminosilicate glasses, respectively measured at the maximum of the emission and excitation bands. The position of the maxima changes depending on the presence or the amount of $\mathrm{Al}$ (see Table 2).

in the excitation bands, thus the Stokes shifts are really wide-ranging (from 4611 up to $7767 \mathrm{~cm}^{-1}$; Table 2). The presence of the components at lower wavelengths in the excitation bands for silica preforms, along with the wider splitting of the emission components (Fig. 5), suggests the presence a/o combination of different effects: the presence of intrinsic silica defects, a charge-transfer (CT, i.e. $\mathrm{Ce}^{4+}$ trapping electrons) that gives rise to the broad bands at lower wavelengths, or to the ability of $\mathrm{Ce}^{3+}$ to form $\mathrm{Ce}^{4+}$ by trapping holes. Because the component at $\sim 275 \mathrm{~nm}$ linearly increases with the $\mathrm{Ce}^{3+} / \Sigma \mathrm{Ce}$ ratios, we are more likely to assign it to trapped hole centers. As a matter of fact, this band,

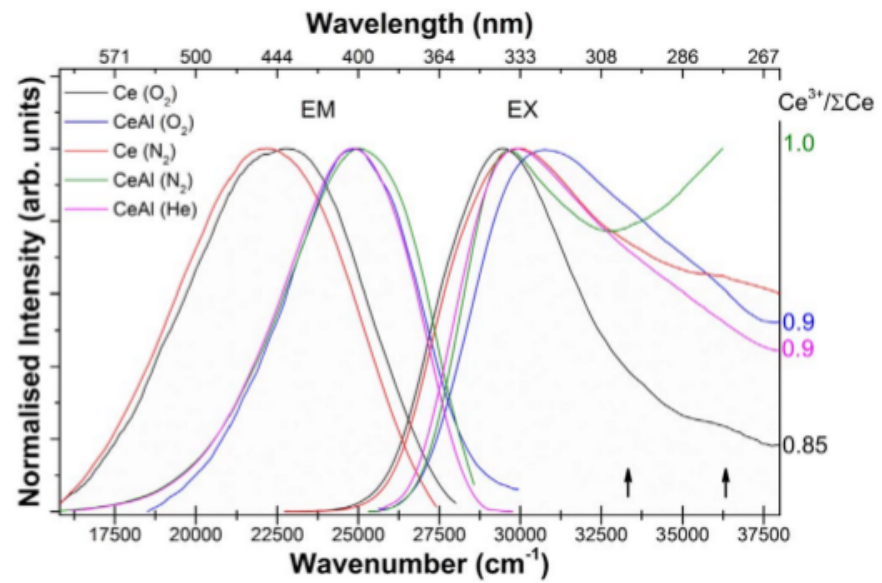

Fig. 5. Excitation (EX) and emission (EM) spectra for some of the Ce-activated silica preforms here investigated, respectively measured at the maximum of the emission and excitation bands. In the excitation spectra, there is the occurrence of a broad contribution at lower wavelengths. Ce redox ratios are reported for sake of clarity.

in all the samples here investigated, occurs only for low amount of $\mathrm{Ce}^{4+}$ species. Indeed, the contribution in the excitation spectra at high frequencies start to be pronounced only in the Al-rich silicate glasses (NAC66.18), which is very similar to that observed in the Al-free silica preform collapsed under $\mathrm{O}_{2}$. Hence, based on the estimated Ce redox ratios we defined that $\mathrm{Ce}^{3+} / \Sigma \mathrm{Ce}>0.85 \pm 0.07$ is the limit for the appearance of the component at $\sim 275 \mathrm{~nm}$.

Table 2

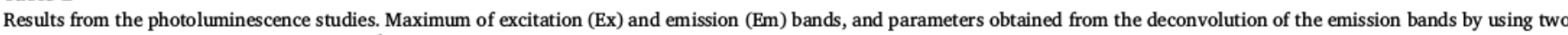
Gaussian $\left(\mathrm{G}^{\star}\right)$ functions. All values as $\mathrm{cm}^{-1}$. The Ce redox ratio is reported for sake of clarity (error \pm 0.07 ).

\begin{tabular}{|c|c|c|c|c|c|c|c|c|c|c|}
\hline Label & $\mathrm{Ce}^{3+} / \Sigma \mathrm{Ce}$ & Ex & $\mathrm{Em}$ & FWHM Em & Stokes shift & Deconvol & n emission & $\mathrm{ds}\left(\mathrm{cm}^{-1}\right)$ & & \\
\hline & & $\left(\mathrm{cm}^{-1}\right)$ & $\left(\mathrm{cm}^{-1}\right)$ & $\left(\mathrm{cm}^{-1}\right)$ & $\left(\mathrm{cm}^{-1}\right)$ & 1 st $G^{*}$ & FWHM 1 & 2nd $G^{\star}$ & FWHM 2 & Splitting ground $4 f$ leve \\
\hline NAC 66.00 & 0.35 & $28,169.0$ & $22,962.1$ & 5352.1 & 5206.9 & $23,915.2$ & 3453.5 & $21,709.1$ & 4895.6 & 2206.1 \\
\hline NAC66.01 & 0.37 & $28,686.2$ & $23,310.0$ & 5526.6 & 5376.1 & $24,108.4$ & 3967.3 & $21,876.9$ & 5477.2 & 2231.5 \\
\hline NAC66.10 & 0.5 & $28,011.2$ & $22,573.4$ & 5377.6 & 5437.8 & $23,733.2$ & 3523.7 & $21,452.2$ & 4832.9 & 2281.0 \\
\hline NAC66.18 & 0.85 & $28,885.0$ & $24,271.8$ & 4964.9 & 4613.2 & $24,939.2$ & 3484.9 & $22,944.3$ & 4775.6 & 1995.0 \\
\hline $\mathrm{Ce}\left(\mathrm{N}_{2}\right)$ & - & $29,940.1$ & $22,172.9$ & 6203.0 & 7767.2 & $23,840.8$ & 3909.7 & $21,137.0$ & 5286.7 & 2703.7 \\
\hline $\mathrm{Ce}\left(\mathrm{O}_{2}\right)$ & 0.85 & $29,455.1$ & $21,834.1$ & 5736.0 & 7621.0 & $23,118.0$ & 3535.6 & $20,734.0$ & 5328.3 & 2384.1 \\
\hline $\operatorname{CeAl}\left(\mathrm{N}_{2}\right)$ & 1 & $29,673.6$ & $25,062.7$ & 4842.8 & 4610.9 & $25,808.9$ & 3264.3 & $23,768.8$ & 4807.4 & 2040.2 \\
\hline $\mathrm{CeAl}\left(\mathrm{O}_{2}\right)$ & 0.9 & $30,864.2$ & $24,691.4$ & 4698.3 & 6172.8 & $25,199.4$ & 3645.5 & $23,205.4$ & 4841.7 & 1993.9 \\
\hline $\mathrm{CeAl}(\mathrm{He})$ & 0.9 & $29,770.8$ & $24,937.7$ & 4764.8 & 4833.1 & $25,464.7$ & 3468.1 & $23,428.7$ & 4813.0 & 2036.0 \\
\hline
\end{tabular}




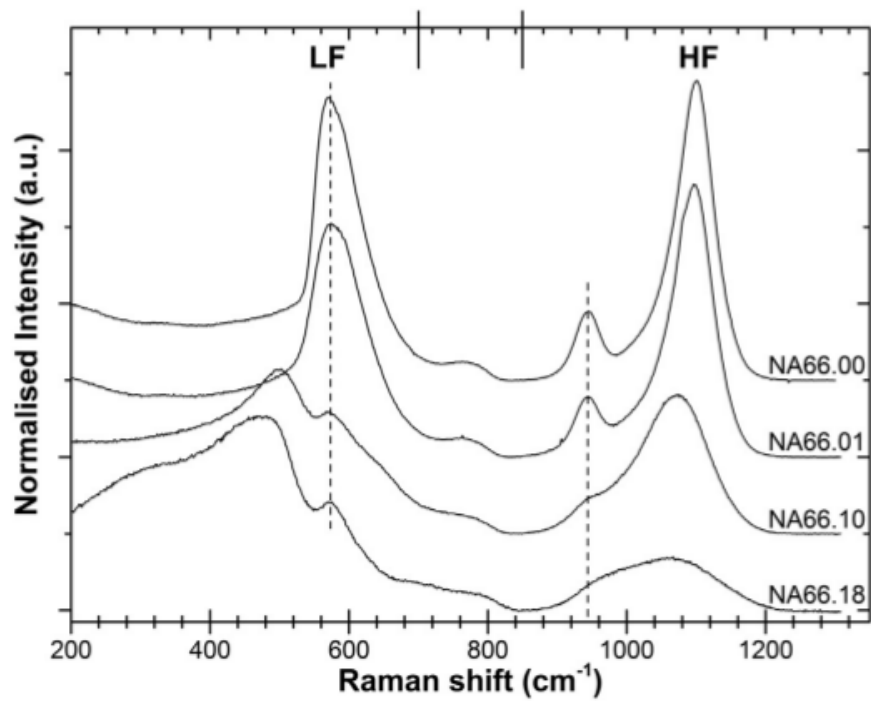

Fig. 6. Raman spectra for Ce-free aluminosilicate glasses with different $\mathrm{Al} / \mathrm{Na}$ molar ratios. Letters indicate the position of the low frequency (LF) and high frequency (HF) regions. By increasing the $\mathrm{Al}$ content in the glasses, there is marked shift of the main bands toward lower frequencies. Vertical dotted lines are guidelines for the position of the bands at $\sim 570 \mathrm{~cm}^{-1}$ and $\sim 945 \mathrm{~cm}^{-1}$.

\subsection{Raman spectroscopy}

For the interpretation of the variations of Ce redox ratio and optical properties in glasses and fiber preforms, we need to take into account the variation in the glass structure occurring by introducing aluminum, and by changing the $\mathrm{Al} / \mathrm{Na}$ ratio. Therefore, Raman spectra both with excitation lasers at $488 \mathrm{~nm}$ and $532 \mathrm{~nm}$ have been collected for all the glasses: undoped and Ce-bearing aluminosilicate glasses and Ce-activated fiber preforms.

\subsubsection{Ce-free series: NA66.y glasses}

Several authors studied the origin of the contributions in the Raman spectra of silicate-based glasses, both from calculated or measured vibrational density of states, and thus, we can relate the bands between 850 and $1300 \mathrm{~cm}^{-1}$ to $\mathrm{Si}-\mathrm{O}$ stretching in different $Q^{n}$ tetrahedral units, ( $n$ is the number of bridging oxygens and $Q$ the four-fold coordinated cation - e.g. Si, Al. e.g. fully polymerized $=Q^{4}$; e.g. [38-41]. and references therein).

Spectra of undoped NA66.y glasses are reported in Fig. 6, where the evolution of the Raman bands depending on the $\mathrm{Al} / \mathrm{Na}$ ratio can be appreciated. All spectra have been normalised to the total area. In the following we discuss the Raman vibrations based on their positions, accordingly to Le Losq et al. [42,43]: the low frequency region (LF $\left.250-700 \mathrm{~cm}^{-1}\right)$, the intermediate region $\left(700-850 \mathrm{~cm}^{-1}\right)$, and the high frequency region ( $\mathrm{HF}$ or $Q$-range, $850-1300 \mathrm{~cm}^{-1}$ ), and we use the nomenclature adopted by $[42,43]$ for vibrational modes in the $Q$ range: band at $\sim 945 \mathrm{~cm}^{-1}$ related to $\mathrm{Si}-\mathrm{O}$ stretching in $Q^{2}$ species, band at $\sim 1050 \mathrm{~cm}^{-1}$ related to $T_{2}$ stretching vibrational mode, and band at $\sim 1100 \mathrm{~cm}^{-1}$ associated to stretching in $Q^{3}$ species. The contributions at $\sim 1130$ and $\sim 1160 \mathrm{~cm}^{-1}$ are both linked to stretching vibrational mode of $Q^{4}$ species, and respectively called $Q^{4, I I}$ and $Q^{4, I}$.

Interestingly there are not so many studies for peraluminous glasses $(\mathrm{Al} / \mathrm{Na}>1)$ compared to the peralkaline $(\mathrm{Al} / \mathrm{Na}<1)$ ones, thus we refer to previous studies done in NAS systems in the albite joint, where the $\mathrm{SiO}_{2}$ molar content is fixed at $75 \mathrm{~mol} \%$ (NA75 from [43]). The spectrum of undoped NA66.00 glass shows the typical bands for this composition (e.g. [41,44,45].), with a strong band, in the HF region, peaking at $1100 \mathrm{~cm}^{-1}$, and a smaller contribution at $\sim 945 \mathrm{~cm}^{-1}$ (Fig. 6). Consequently, Si occurs mainly in $Q^{3}$ and $Q^{2}$ units, with only a small contribution from $Q^{4}$ units, in agreement with previous studies
$[44,46]$. In the low frequency region for glass NA66.00, the main band is a sharp asymmetric peak at around $570 \mathrm{~cm}^{-1}$. When substituting $\mathrm{Al}$ for $\mathrm{Na}$ in NA66.y glasses, the main bands, both in the low and high frequency regions, decrease in intensity and shift to lower wavenumbers [47]. Indeed, in the low frequency region the main band (associated to $\mathrm{T}-\mathrm{O}-\mathrm{T}$ vibrations) shifts from $\sim 570 \mathrm{~cm}^{-1}$ to $\sim 499 \mathrm{~cm}^{-1}$ by increasing the $\mathrm{Al} / \mathrm{Na}$ ratio. In samples with $\mathrm{Al} /$ $\mathrm{Na}>0.4$ (Fig. 6) appear the shoulder at $\sim 570 \mathrm{~cm}^{-1}$, which can be related to the defect-line $\mathrm{D}_{2}$, associated to the breathing mode of $(\mathrm{SiO})_{3}$ rings, and also there is the increase of the tail at lower frequencies, which can be related to the stretching of higher membered rings ([43] and references therein). The peraluminous sample $(\mathrm{Al} / \mathrm{Na}>1$; NA66.18 in Fig. 6) additionally has a contribution at lower frequency $\left(\sim 280 \mathrm{~cm}^{-1}\right)$ assigned to $\mathrm{T}-\mathrm{O}-\mathrm{T}$ bending vibrations, and also a small broad band in the intermediate region $\left(\sim 700 \mathrm{~cm}^{-1}\right)$. In the high frequency region or $Q$-range there is a systematic shift of the main band from $1100 \mathrm{~cm}^{-1}$ to $1059 \mathrm{~cm}^{-1}$ when substituting $\mathrm{Al}$ for $\mathrm{Na}$, along with a net decrease of the intensities (Fig. 6). Moreover, there is a systematic increase of the contribution around $1050 \mathrm{~cm}^{-1}$, which has been related to $T_{2}$ stretching vibrational mode where two oxygen atoms move closer to the central $\mathrm{Si}$ atom, whereas the other two oxygen atoms of $\mathrm{TO}_{4}$ tetrahedra move away [48]. The occurrence of this band in various silicate glasses indicates that it arises from a T-O stretching type which is different from the $\mathrm{T}-\mathrm{O}$ stretching forming the $Q^{n}$ bands ([42]).

The high-frequency region has been analyzed in detail by taking into account the different approaches described by Le Losq and coauthors $[42,43]$. The deconvolution has been carried out with Gaussian functions on background subtracted spectra in the $850-1250 \mathrm{~cm}^{-1}$ frequency range. Examples of the Raman $Q$-range deconvolution are shown in Fig. 7, where the experimental spectra, the Gaussian functions used, along with the residuals, are reported. As stated above, we use the nomenclature adopted by $[42,43]$ for vibrational modes in the $Q$-range, hence five Gaussian have been used to fit the glasses in the peralkaline range ( $\mathrm{Al} / \mathrm{Na}<1$ ), whereas $Q^{2}$ and $Q^{3}$ peaks are not included in the fit of sample NA66.18 since no NBOs are expected in this glass composition (based on previous Raman and NMR studies in CAS, NAS and MAS systems; e.g. $[43,47,49]$. (Fig. 7a-d). The evolution of the $Q$-species by changing the $\mathrm{Al} / \mathrm{Na}$ ratio is in agreement with the study done in the albite joint (in Fig. 7e, NA75.y from [43]), albeit the different proportions for the $Q^{n}$ species due to the different $\mathrm{SiO}_{2}$ content. Indeed, when substituting $\mathrm{Al}$ for $\mathrm{Na}$, there is a decrease of the proportion of $Q^{3}$ species, alongside with the increases of $Q^{4, I I}$ species (Fig. 7e). The occurrence of highly coordinated $\mathrm{Al}$ species in the peraluminous region was verified by NMR studies in the albite joint [43], and being the trend for our glasses very similar, we can assume an almost identical behaviour.

All the observation done on undoped glasses are going to be used for the interpretation of Ce surrounding in the doped series.

\subsubsection{Ce-bearing series: NAC66.y glasses}

In Fig. 8 are reported the Raman spectra for the undoped (NA66.y, black lines) and Ce-bearing aluminosilicate glass compositions (NAC66.y, blue lines). In order to compare the Raman spectra for Cebearing glasses and the undoped ones there is the need to take into account both the modifications due to the different $\mathrm{Al} / \mathrm{Na}$ ratios, and also the different Ce redox ratios. To highlight the spectral changes due to the Ce presence for each sample, we have normalised the intensity to the maximum of the band in the Q-range. When introducing Ce in the aluminosilicate glasses with $\mathrm{Al} / \mathrm{Na}<1$ (Fig. 8a.c), there are a few modifications, and in particular, in the Q-range, differences are mainly associated to the $T_{2}$ stretching vibrational mode and $Q^{3}$ stretching mode, along with a slightly shift toward lower frequencies, and to the occurrence of a small feature around $870 \mathrm{~cm}^{-1}$. Remarkably, this latter band is higher for the $\mathrm{Al}$-free (NAC66.00) and $1 \mathrm{~mol} \% \mathrm{Al}_{2} \mathrm{O}_{3}$ (NAC66.01) glasses (blue lines respectively in Fig. 8a and b).

The strongest differences in the Raman signal can be observed for 

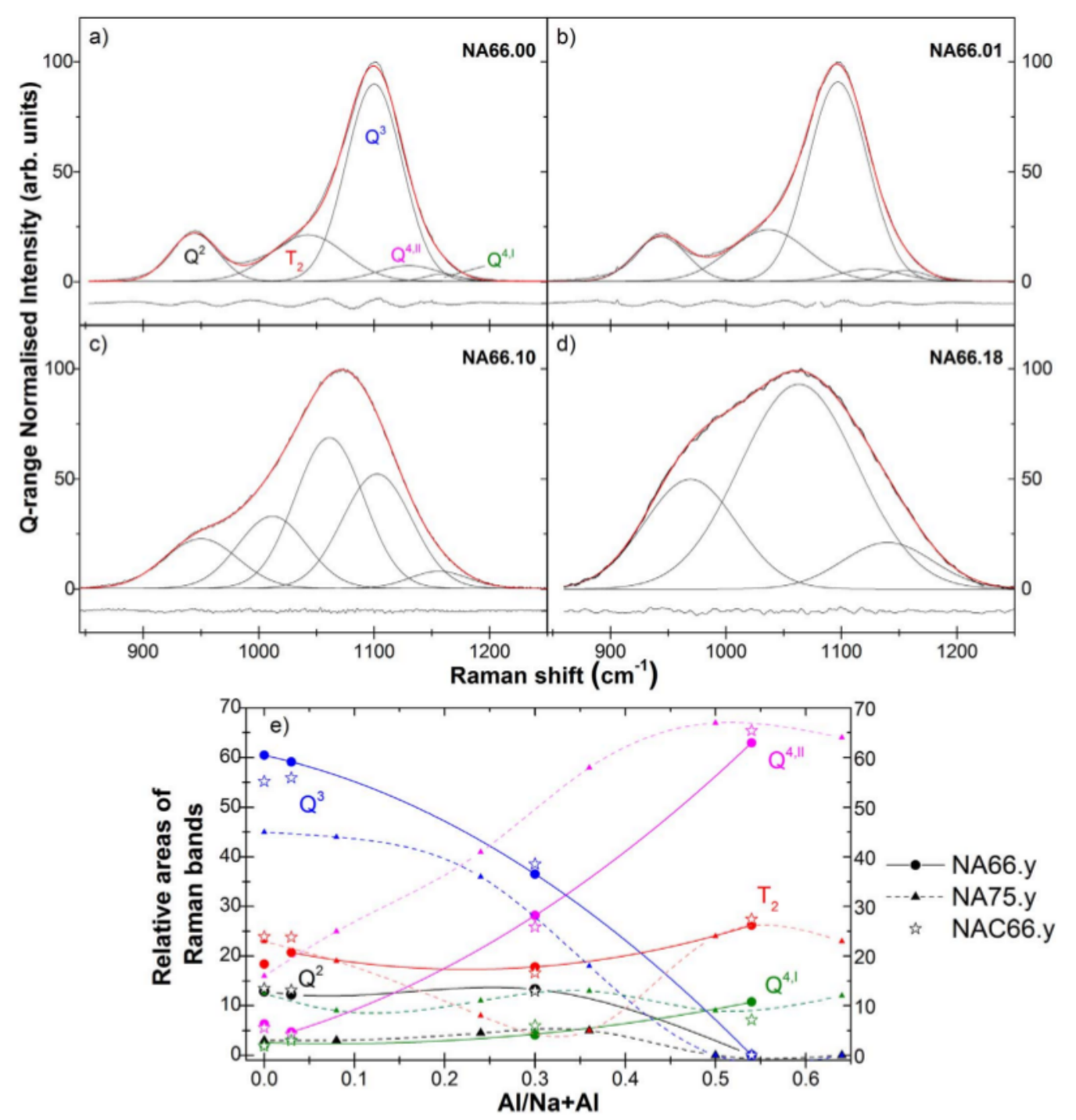

Fig. 7. a-d: Normalised Raman spectra in the high frequency region for NA66.y glasses with different $\mathrm{Al} / \mathrm{Na}$ molar ratios. The Gaussian functions used for the deconvolution of the $Q$-ranges are reported, along with the theoretical spectra obtained (red lines) and the residuals. For assignment of the bands, see text. e) Relative areas of Raman bands in the $\mathrm{HF}$ region vs. the $\mathrm{Al} /(\mathrm{Na}+\mathrm{Al})$ molar ratio for the aluminosilicate glasses NA66.y and NAC66.y studied here, and for comparison glasses NA75.y from [43]. Solid and dashed lines are guidelines for the eye. (For interpretation of the references to color in this figure legend, the reader is referred to the web version of this article.) the glass with the highest amount of $\mathrm{Al}(\mathrm{Al} / \mathrm{Na}>1$ : NAC66.18, Fig. 8d). When Ce is added, the whole $Q$-range shifts toward higher frequencies and both intensity and broadening of the main band in the low frequency region increases. From the deconvolution of the Q-ranges for the Al rich glasses (respectively NA66.18 and NAC66.18) we observed a relative increases of the $T_{2}$ and $Q^{4, I I}$ units for the Ce-doped glass (see Figs. 7e and 8d).

In the low-frequency region as well, some modifications occur when introducing Ce. The main band in the low-frequency portion shows different intensities depending on the presence of $\mathrm{Ce}$, and it slightly moves toward lower frequencies. Moreover, there are a few modifications in the tail of the main band that might originate from variations in the $\mathrm{T}-\mathrm{O}-\mathrm{T}$ bonding. However, all the differences observed in the lower frequency region are challenging to assign because dissimilarities could be ascribed to several factors, including baseline modifications, or luminescence centers, etc.

In Na-silicate glasses, by X-ray photoelectron spectroscopy, [50] suggested that $\mathrm{Ce}$ ions enter the network as a glass intermediate, whereas [51,52] reported that $\mathrm{Ce}^{3+}$ acts as a network modifier, respectively in aluminosilicophosphate and sodium germanate glasses.

In our aluminosilicate glasses, with $\mathrm{Al} / \mathrm{Na}$ ratio $<0.5$, the remarkable variations are: i) the modifications of the low frequency tail when adding $\mathrm{Ce}$, ii) the increase of the $T_{2}$ component at $\sim 1030 \mathrm{~cm}^{-1}$, and iii) the presence of the small feature around $870 \mathrm{~cm}^{-1}$. Since in these glasses it was estimated a $\mathrm{Ce}^{3+} / \Sigma \mathrm{Ce}=0.35-0.5( \pm 0.07)$, we assume that this latter band is mainly associated to the prevalent presence of oxidized species. The presence of prevalent $\mathrm{Ce}^{3+}$ species (NAC66.18: $\mathrm{Ce}^{3+} / \Sigma \mathrm{Ce}=0.85 \pm 0.07$ ) visibly affects the Raman signal, mainly in the HF region, where the whole $Q$-range shifts toward higher frequencies, as a result of the relative increase of $Q^{4, I I}$ units, which have smaller $\mathrm{T}-\mathrm{O}-\mathrm{T}$ angles with respect to $Q^{4, \mathrm{I}}$ units [43]. Theoretical calculations [53] have shown that when $\mathrm{Al}$ is substituted for $\mathrm{Si}$, the average $\mathrm{T}-\mathrm{O}$ bond length increases, and the average $\mathrm{Si}-\mathrm{O}-\mathrm{Al}$ angle decreases, in agreement with experimental studies [54,55]. It follows that in a system where not enough cations $\left(\mathrm{Na}^{+}\right)$are available to charge balancing $\mathrm{Al}^{3+}$ cations (leading to higher $\mathrm{Al}$ coordinations [5] $\mathrm{Al}$ and/or [6] $\mathrm{Al}$ ), $\mathrm{Ce}^{3+}$ enhances the stabilization of higher amount of $\mathrm{Al} 4$-fold coordinated. Therefore, we can assume that $\mathrm{Ce}^{3+}$ mainly behaves as charge compensator of neighboring $\mathrm{Al}$ polyhedral.

\subsubsection{Ce-activated silica preforms}

Raman spectra of the Ce-activated silica preforms were collected both in the silica cladding and in the doped/codoped core. For Al-free preforms, between the core and the cladding, only small variations occur in the Raman spectra, whereas for Al codoped preforms, significant differences can be observed (Fig. 9). The spectrum collected in the cladding resembles the spectra of pure $\mathrm{SiO}_{2}$, with the well pronounced $D_{1}$ and $D_{2}$ "defect" lines in the LF region, and the relatively less intense vibrational features above $950 \mathrm{~cm}^{-1}$ (red spectrum in Fig. 9 a). $D_{1}$ and $D_{2}$ lines are associated to the breathing modes of 


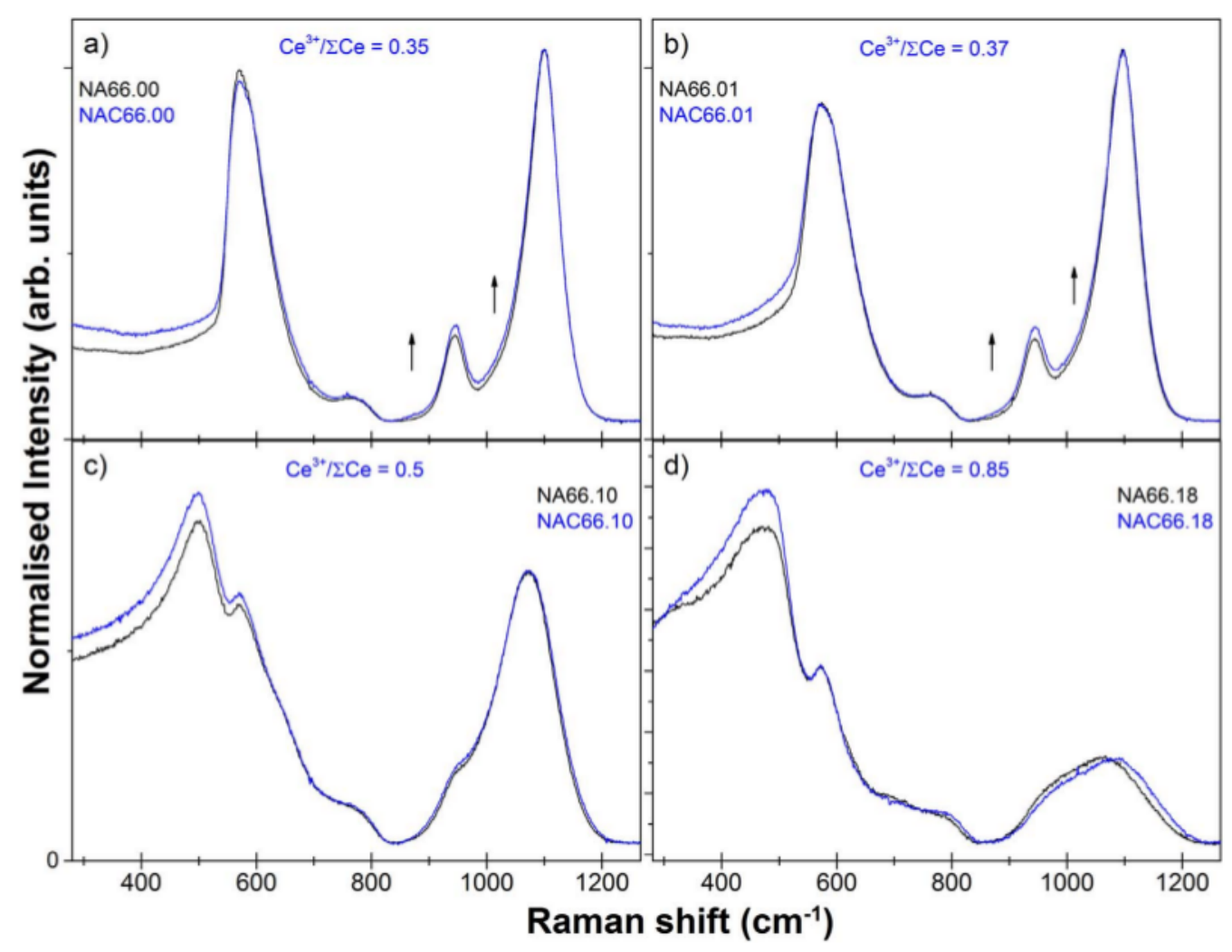

Fig. 8. a-d) Raman spectra normalised to the maximum of the band in the Q-range, for undoped (black lines), and Ce-doped glasses (blue lines). The $\mathrm{Ce}^{3+} / \Sigma \mathrm{Ce}$ ratios for $\mathrm{Ce}$ bearing glasses are reported. Black arrows point to the main modifications occurring in the bands at high frequencies. (For interpretation of the references to color in this figure legend, the reader is referred to the web version of this article.

$(\mathrm{SiO})_{4}$ - and $(\mathrm{SiO})_{3}$-rings, respectively, whereas the broader band of the spectra centered at $\sim 436 \mathrm{~cm}^{-1}$ corresponds to the $\mathrm{Si}-\mathrm{O}-\mathrm{Si}$ vibration modes $[56,57]$. The spectrum related to the $\mathrm{Al} / \mathrm{Ce}$ codoped core (blue spectrum in Fig. 9a), in the low frequency region, resembles that of the cladding, but with marked variations in the relative intensities of the $D_{1}$ and $\mathrm{D}_{2}$ lines, and this suggests that $\mathrm{Al}$ partially modifies the population of the small $(\mathrm{SiO})_{4}$ - and $(\mathrm{SiO})_{3}$-rings. In the high frequency domain, the $Q$-range of the cladding presents two well-separated peaks, centered respectively around $1056 \mathrm{~cm}^{-1}$ and $1188 \mathrm{~cm}^{-1}$, whereas the $\mathrm{Al} / \mathrm{Ce}$ codoped core has a much broader contribution. The deconvolution of the Q-ranges (Fig. 9b) highlights that both high frequency regions can be fitted by using three Gaussians, like the aluminosilicate glass NA66.18, since there is a high polymerized network where no NBOs are expected. The contribution at $\sim 1056 \mathrm{~cm}^{-1}\left(T_{2}\right)$ is quite narrow and it remains almost constant either in the cladding or in the codoped core, similarly to the contribution at higher frequencies (attributed to $Q^{4, \mathrm{I}}$ species), that has almost the same FWHM and frequency position. On the other hand, strong variations can be observed for the central peak, associated to $Q^{4, I I}$ species, that strongly rises and shifts toward lower frequencies (Fig. 9b). Since both $T_{2}$ and $Q^{4, I}$ species remains almost constant, we can assume that, in the codoped center of fiber preforms, the 4-fold coordinated $\mathrm{Al}^{3+}$ enters in $Q^{4, I I}$ units, in agreement with previous observations done in peraluminous systems ([43] and references therein).

\subsection{Structural considerations}

The addition of $\mathrm{Al}_{2} \mathrm{O}_{3}$ to alkali silicate glass (with $\mathrm{Al} /$ alkali $<1$ )
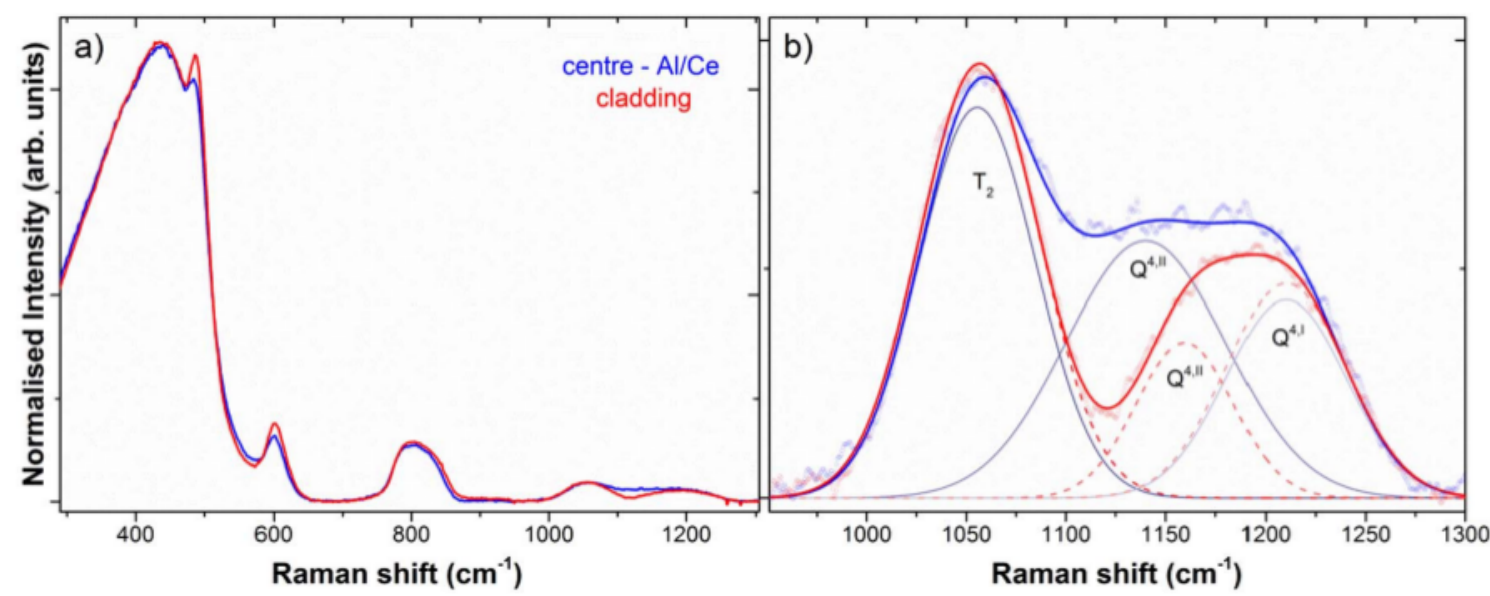

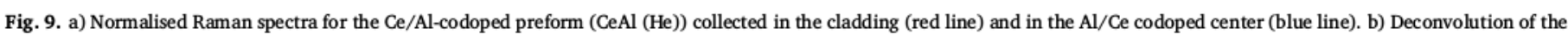

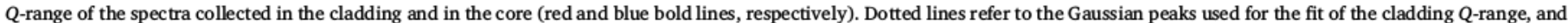

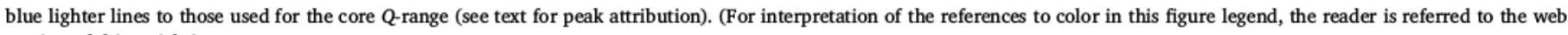
version of this article.) 


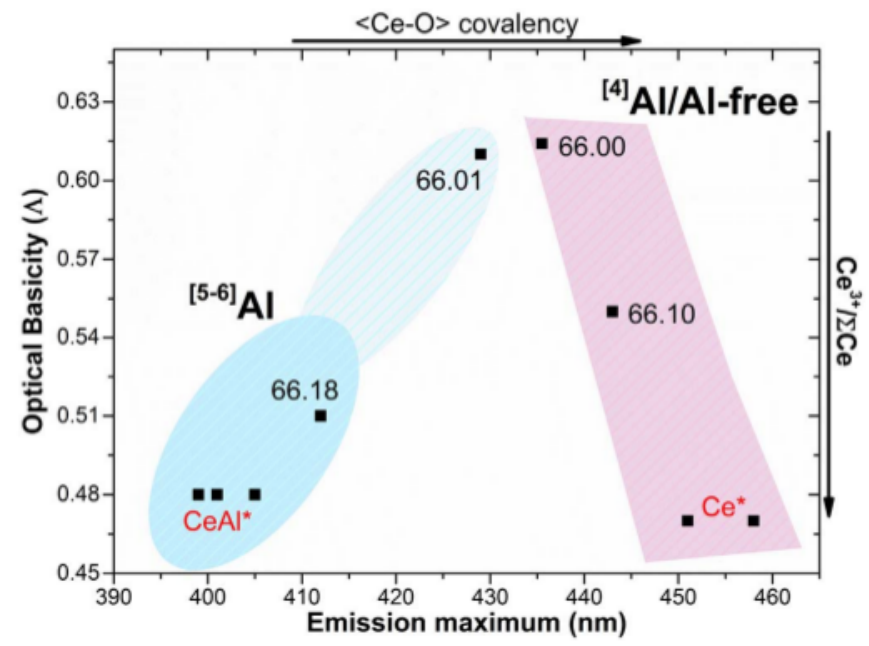

Fig. 10. Maximum of the $\mathrm{Ce}^{3+}$ emission bands as a function of the theoretical optical basicity $(\Lambda)$ values for silicate glasses and Silica preforms (*red labels). For the glasses here investigated we propose two different regions depending on $\mathrm{Al}$ coordination. (For interpretation of the references to color in this figure legend, the reader is referred to the web version of this article.)

mainly induces the $\mathrm{Na}^{+}$ions to modify their structural role from network-modifier to charge compensator, till no more non-bridging oxygen (NBO) atoms remain. On the other hand, beyond the metaluminous join, the exceeding amount of $\mathrm{Al}_{2} \mathrm{O}_{3}$, leads $\mathrm{Al}^{3+}$ cations into higher coordinations ([5] Al or [6] Al) ([43] for NAS glasses; $[49,58,59]$ for CAS glasses; [60] for MAS glasses). Moreover, for low content of Al (1-2 mol\%), NMR studies of the ternary systems have highlighted the occurrence of $\mathrm{Al}$ 6-fold coordinated [61].

Molecular Dynamics simulations [62] indicates that $\mathrm{Ce}^{3+}$ ions are preferentially surrounded by aluminum oxygen polyhedra instead of silicon ones. In the glasses here investigated, from the Raman spectra, we observed that part of the $\mathrm{Al}$ is 4-fold coordinated, but we also expect higher coordinations ([5,6] $\mathrm{Al})$ [43]. If $\mathrm{Ce}^{3+}$ ions are preferentially surrounded by $\mathrm{Al}$ polyhedra with respect $\mathrm{Si}$ ones, thus $\mathrm{Ce}^{3+}$ may play a charge balance role for neighboring $\mathrm{Al}$ cations, leading to variations in the Ce surrounding, depending on the aluminum oxygen polyhedral.

Aluminosilicate glasses with $0.1<\mathrm{Al} / \mathrm{Na}<1$, and Al-free silica preforms have very broad emission bands centered around $440 \mathrm{~nm}$, whereas $\mathrm{Al} / \mathrm{Ce}$ codoped silica preforms, and NAC66.18 glass, have a strong blue shift of the emission bands (Figs. 4-5). The observed blue shift can be rationalized by the nephelauxetic effect, and thus to variations of the distance between $\mathrm{Ce}^{3+}$ and its ligands, and/or to variations of the covalency of the bonds. The smaller Stokes shifts observed (Table 2) for glasses having $\mathrm{Al}$ present in 4-fold coordination and, presumably, in higher coordinations, indicate that the covalency of $\langle\mathrm{Ce}-\mathrm{O}\rangle$ bonds decreases, in agreement with a charge compensation role of Ce species. Moreover, the blue shift suggests a decrease of the local crystal field splitting of the 5d level [7]. In contrast with Albearing glasses, the shift to lower energies indicates more covalent and strong crystal field surroundings.

The theoretical optical basicity $(\Lambda)$ values for the glasses here investigated can be used satisfactorily to predict the Ce redox states, in agreement with previous studies [28-30]. By increasing the optical basicity (OB), the content of oxidized species in the glasses increases, and by increasing $\mathrm{Al}$ content there is a decrease of the $\mathrm{OB}$, since the electron donor ability is highly influenced by the surrounding network former cations. Also for this reason, the photoluminescence does not follow a linear trend (Fig. 10) by changing the bulk optical basicity. Indeed, the photoluminescence cannot be easily correlated to the optical basicity, in contrast with [37] or other REE-bearing glasses (e.g. Eu $[63,64])$ since the chemical control is largely the primary factor influencing Ce structural role.
There are two trends when correlating optical basicity and maximum of the emission band for aluminosilicate glasses and silica preforms (Fig. 10). Hence, we describe the variations of the photoluminescence based on the coordination environment around $\mathrm{Al}$, since it modifies neighborhood of cerium ions (Fig. 10). Glasses without $\mathrm{Al}$ or with $\mathrm{Al}$ entirely 4-fold coordinated have the emission maximum at higher wavelengths, whereas glasses where $\mathrm{Al}$ is expected to be present with higher coordinations $([5,6] \mathrm{Al})$ have the emission maximum at much lower wavelengths (Fig. 10). The doping level in the fiber preforms cannot produce variations in the optical basicity, thus it this mandatory to contemplate variations in the $\mathrm{Ce}^{3+}$ surrounding (symmetry a/o coordination), and in turn, in its structural role.

\section{Conclusions and remarks}

We investigated Ce redox ratio, optical properties and glass structure of aluminosilicate glasses with variable $\mathrm{Al} / \mathrm{Na}$ ratios and Ce-activated silica preforms, with the aim to quantitatively describe the correlation between aluminum and cerium.

Ce redox behaviour is strongly linked to the optical basicity of the glasses, and the substitution of $\mathrm{Al}$ for $\mathrm{Na}$ in aluminosilicate glasses, and the $\mathrm{Al}$ codoping in Ce-activated preforms, strongly stabilizes reduced $\mathrm{Ce}$ species. $\mathrm{Ce}^{3+}$ has the same ionic radii of $\mathrm{Na}^{+}[65]$ thus the stabilization of reduced species with $\mathrm{Al}$ incorporation can be seen as a greater capacity of $\mathrm{Ce}^{3+}$ to behave as charge compensator for $\mathrm{Al}$ compared to $\mathrm{Na}$.

Raman spectroscopy has evidenced that substitution of $\mathrm{Al}$ for $\mathrm{Na}$ in aluminosilicate glasses produces several modifications in the glass structure. In the glass where $\mathrm{Ce}^{3+}$ is the predominant species (NAC66.18), the Raman spectrum show clear variations, with the whole $Q$-range shifted toward higher frequencies, as a result of the relative increase of $Q^{4, I}$ units (Fig. 7e). The same observation was done for $\mathrm{Al}$ codoped silica preforms, where the feature associated to $Q^{4, I I}$ species strongly rises and shifts toward lower frequencies, because it accommodates the 4-fold coordinated $\mathrm{Al}^{3+}$.

Photoluminescence studies show that cerium has two different emissions. Al presence induces different environments around $\mathrm{Ce}^{3+}$ ions, and the smaller Stokes shifts altogether with the emission shift, indicate that the covalency of $\langle\mathrm{Ce}-\mathrm{O}\rangle$ bonds decreases, in agreement with the $\mathrm{Ce}^{3+}$ charge-compensating role of neighboring $\mathrm{Al}$ polyhedral. Additional bands in the UV region occur only for lower amount of $\mathrm{Ce}^{4+}$ $\left(\mathrm{Ce}^{3+} / \Sigma \mathrm{Ce}>0.85 \pm 0.07\right)$, and they can be ascribed to the presence a/o combination of different effects: the presence of intrinsic silica defects, a charge-transfer (CT, i.e. $\mathrm{Ce}^{4+}$ trapping electrons) that gives rise to the broad bands at lower wavelengths, or to the ability of trivalent $\mathrm{Ce}$ to form $\mathrm{Ce}^{4+}$ by trapping holes. Because of the linear increases of the component at $\sim 275 \mathrm{~nm}$ with increasing $\mathrm{Ce}^{3+} / \Sigma \mathrm{Ce}$ ratios, we are more likely to assign it to trapped hole centers.

Based on these results we could speculate that photodarkening attenuation in $\mathrm{Ce} / \mathrm{Al}$ codoped fibers mainly is due to the stabilization of higher amounts of $\mathrm{Ce}^{3+}$ in the amorphous structure thanks to $\mathrm{Al}$ addition, combined with the ability of trivalent $\mathrm{Ce}$ to form $\mathrm{Ce}^{4+}$ by trapping holes, reducing the formations of $\mathrm{Al} / \mathrm{Si}$ defects (Si/Al-trapped hole centers). In order to verify our hypothesis, further experiments on $\mathrm{Tm}-\mathrm{Ce} / \mathrm{Al}$ codoped fibers are already planned.

\section{Acknowledgments}

The authors thank SOLEIL and ESRF for providing beamtime (respectively, experiments 20150518 and MA3203), and the beamlines staff for support. MV was supported by ANR project Nice-DREAM (ANR-14-CE07-0016-03).

\section{References}

[1] R. Reisfeld, Industrial applications of rare earths in fiber optics, luminescent solar concentrators and lasers, Inorg. Chim. Acta 140 (1987) 345-350, http://dx.doi.org/ 
10.1016/S0020-1693(00)81119-6.

[2] M.J. Weber, Science and technology of laser glass, J. Non-Cryst. Solids 123 (1990) 208-222, http://dx.doi.org/10.1016/0022-3093(90)90786-L.

[3] R. Reisfeld, A. Patra, G. Panczer, M. Gaft, Spectroscopic properties of cerium in solgel glasses, Opt. Mater. (Amst). 13 (1999) 81-88, http://dx.doi.org/10.1016/ S0925-3467(99)00015-4.

[4] G. Liu, B. Jacquier, Spectroscopic properties of rare earths, Opt. Mater. (2005), http://dx.doi.org/10.1007/3-540-28209-2.

[5] M. Sato, S.W. Kim, Y. Shimomura, T. Hasegawa, K. Toda, G. Adachi, Rare earthdoped phosphors for white light-emitting diodes, Handb. Phys. Chem. Rare Earths. 49 (2016) 1-128.

[6] G. Blasse, A. Bril, Investigation of some $\mathrm{Ce}^{3+}$-activated phosphors, J. Chem. Phys. 47 (1967) 5139-5145, http://dx.doi.org/10.1063/1.1701771.

77] Y. Ishii, K. Arai, H. Namikawa, M. Tanaka, A. Negishi, T. Handa, Preparation of cerium-activated silica glasses: phosphorus and aluminum codoping effects on absorption and fluorescence properties, J. Am. Ceram. Soc. 70 (1987) 72-77.

[8] M.L. Brandily-Anne, J. Lumeau, L. Glebova, L.B. Glebov, Specific absorption spectra of cerium in multicomponent silicate glasses, J. Non-Cryst. Solids (2010) 2337-2343, http://dx.doi.org/10.1016/j.jnoncrysol.2010.02.020.

[9] A.D. Burnham, A.J. Berry, The effect of oxygen fugacity, melt composition, temperature and pressure on the oxidation state of cerium in silicate melts, Chem. Geol. 366 (2014) 52-60, http://dx. doi.org/10.1016/j.chemgeo.2013.12.015.

[10] A. Herrmann, H.A. Othman, A.A. Assadi, M. Tiegel, S. Kuhn, C. Rüssel, Spectroscopic properties of cerium-doped aluminosilicate glasses, Opt. Mater. Express. 5 (2015) 720, http://dx.doi.org/10.1364/OME.5.000720.

[11] Z. Assefa, R.G. Haire, D.L. Caulder, D.K. Shuh, Correlation of the oxidation state of cerium in sol-gel glasses as a function of thermal treatment via optical spectroscopy and XANES studies, Spectrochim. Acta Part A Mol. Biomol. Spectrosc. 60 (2004) 1873-1881.

[12] M. Fasoli, A. Vedda, A. Lauria, F. Moretti, E. Rizzelli, N. Chiodini, F. Meinardi, M. Nikl, Effect of reducing sintering atmosphere on Ce-doped sol-gel silica glasses, J. Non-Cryst. Solids 355 (2009) 1140-1144, http://dx.doi.org/10.1016/j. jnoncrysol.2009.01.043.

[13] G.K. Das Mohapatra, A spectroscopic study of cerium in lithium-alumino-borate glass, Mater. Lett. 35 (1998) 120-125, http://dx.doi.org/10.1016/S0167-577X(97) 00232-2.

[14] R. Reisfeld, H. Minti, A. Patra, D. Ganguli, M. Gaft, Spectroscopic properties of cerium in glasses and their comparison with crystals, Spectrochim. Acta Part A Mol. Biomol. Spectrosc. 54 (1998) 2143-2150, http://dx.doi.org/10.1016/S13861425(98)00131-0.

[15] M. Engholm, P. Jelger, F. Laurell, L. Norin, Improved photodarkening resistivity in ytterbium-doped fiber lasers by cerium codoping, Opt. Lett. 34 (2009) 1285-1287, http://dx.doi.org/10.1364/OL.34.001285.

[16] N. Ollier, M. Guzik, G. Boulon, Suppression mechanism of radiation-induced darkening by $\mathrm{Ce}$ doping in $\mathrm{Al} / \mathrm{Yb} / \mathrm{Ce}$-doped silica glasses: evidence from optical spectroscopy, EPR and XPS analyses, J. Appl. Phys. 120 (2016) 153101, http://dx. doi.org/10.1063/1.4964878.

[17] S. Jetschke, S. Unger, A. Schwuchow, M. Leich, J. Kirchhof, Efficient Yb laser fibers with low photodarkening by optimization of the core composition, Opt. Express 16 (2008) 15540, http://dx.doi.org/10.1364/OE.16.015540.

[18] J.-F. Lupi, M. Vermillac, W. Blanc, F. Mady, M. Benabdesselam, B. Dussardier, D.R. Neuville, Steady photodarkening of thulium alumino-silicate fibers pumped at $107 \mu \mathrm{m}$ : quantitative effect of lanthanum, cerium, and thulium, Opt. Lett. 41 (2016) 2771, http://dx. doi.org/10.1364/OL.41.002771.

[19] J.B. MacChesney, P.B. O'connor, H.M. Presby, A new technique for the preparation of low-loss and graded-index optical fibers, Proc. IEEE 62 (1974) 1280-1281, http://dx.doi.org/10.1109/PROC.1974.9608.

[20] J.E. Townsend, S.B. Poole, D.N. Payne, Solution-doping technique for fabrication of rare-earth-doped optical fibres, Electron. Lett. 23 (1987) 329-331, http://dx.doi. org/10.1049/el:19870244.

[21] V. Magnien, D.R. Neuville, L. Cormier, J. Roux, J.L. Hazemann, D. de Ligny, S. Pascarelli, I. Vickridge, O. Pinet, P. Richet, Kinetics and mechanisms of iron redox reactions in silicate melts: the effects of temperature and alkali cations, Geochim. Cosmochim. Acta 72 (2008) 2157-2168, http://dx.doi.org/10.1016/j.gca.2008.02. 007.

[22] D.R. Neuville, L. Hennet, P. Florian, D. de Ligny, In situ high-temperature experiments, Rev. Mineral. Geochem. 78 (2014) 779-800, http://dx.doi.org/10.2138/ rmg.2013.78.19.

[23] M.R. Cicconi, D.R. Neuville, I. Tannou, F. Baudelet, P. Floury, E. Paris, G. Giuli, Competition between two redox states in silicate melts: an in-situ experiment at the Fe K-edge and Eu L3-edge, Am. Mineral. 100 (2015) 1013-1016, http://dx.doi.org/ 10.2138/am-2015-5172.

[24] M.R. Cicconi, Europium (Eu) and Cerium (Ce) in Silicate Glasses: XAS Study of their Oxidation States and Local Environments, Camerino University, $\mathrm{PhD}$ thesis, 2010.

[25] A. Bianconi, A. Marcelli, H. Dexpert, R. Karnatak, A. Kotani, Specific intermediatevalence state of insulating $4 \mathrm{f}$ compounds detected by L 3 X-ray absorption, Phys. Rev. B (1987).

[26] G. Kaindl, G. Schmiester, E.V. Sampathkumaran, P. Wachter, Pressure-induced changes in L_III X-ray-absorption near-edge structure of $\mathrm{CeO}_{2}$ and $\mathrm{CeF}_{4}$ : relevance to 4 f-electronic structure, Phys. Rev. B 38 (1988) 10174-10177, http://dx.doi.org/ 10.1103/PhysRevB.38.10174.

[27] Y. Takahashi, H. Shimizu, A. Usui, H. Kagi, M. Nomura, Direct observation of tetravalent cerium in ferromanganese nodules and crusts by X-ray-absorption nearedge structure (XANES), Geochim. Cosmochim. Acta 64 (2000) 2929-2935, http:// dx.doi.org/10.1016/S0016-7037(00)00403-8.

[28] H.D. Schreiber, An electrochemical series of redox couples in silicate melts: a review and applications to geochemistry, J. Geophys. Res. 92 (1987) 9225-9232, http:// dx.doi.org/10.1029/JB092iB09p09225.

[29] F. Baucke, J. Duffy, Redox reactions between cations of different polyvalent elements in glass melts: an optical basicity study, Phys. Chem. Glasses (1993).

[30] O. Pinet, J. Phalippou, C. Di Nardo, Modeling the redox equilibrium of the Ce4 +/ $\mathrm{Ce} 3+$ couple in silicate glass by voltammetry, J. Non-Cryst. Solids 352 (2006) 5382-5390, http://dx.doi.org/10.1016/j.jnoncrysol.2006.08.034.

[31] J.A. Duffy, M.D. Ingram, An interpretation of glass chemistry in terms of the optical basicity concept, J. Non-Cryst. Solids 21 (1976) 373-410, http://dx.doi.org/10. 1016/0022-3093(76)90027-2.

[32] J.A. Duffy, G.O. Kyd, Ultraviolet absorption and fluorescence spectra of cerium and the effect of glass composition, Phys. Chem. Glasses 37 (1996) 45-48.

[33] A. Lebouteiller, P. Courtine, Improvement of a bulk optical basicity table for oxidic systems, J. Solid State Chem. (1998), httt://dx.doi.org/10.1006/jssc.1997.7722.

[34] P. Dorenbos, 5D level positions of the trivalent lanthanides in inorganic compounds, J. Lumin. 91 (2000) 155-176, http://dx.doi.org/10.1016/S0022-2313(00)00229-5.

[35] P. Dorenbos, Relating the energy of the [Xe]5d1 configuration of $\mathrm{Ce} 3+$ in inorganic compounds with anion polarizability and cation electronegativity, Phys. Rev. B 65 (2002) 235110-1-6, http://dx.doi.org/10.1103/PhysRevB.65.235110.

[36] J.A. Duffy, Polarisability and polarising power of rare earth ions in glass: an optical basicity assessment, Phys. Chem. Glasses 46 (2005) 1-6.

[37] J. Bei, G. Qian, X. Liang, S. Yuan, Y. Yang, Optical properties of Ce3 +-doped oxide glasses and correlations with optical basicity, Mater. Res. Bull. (2007).

[38] P. McMillan, B. Piriou, The structures and vibrational spectra of crystals and glasses in the silica-alumina system, J. Non-Cryst. Solids 53 (1982) 279-298, http://dx.doi. org/10.1016/0022-3093(82)90086-2.

[39] P.F. McMillan, Structural studies of silicate glasses and melts-applications and limitations of Raman spectroscopy, Am. Mineral. 69 (1984) 622-644 (0003-004x/ 84/070E-0622\$0).

[40] B. Mysen, Structure and properties of magmatic liquids, Geochim. Cosmochim. Acta 63 (1999) 95-112.

[41] D.R. Neuville, D. de Ligny, G.S. Henderson, Advances in Raman spectroscopy applied to earth and material, Science (2014), http://dx.doi.org/10.2138/rmg.2013. 78.13.

[42] C. Le Losq, D.R. Neuville, Effect of the $\mathrm{Na} / \mathrm{K}$ mixing on the structure and the rheology of tectosilicate silica-rich melts, Chem. Geol. 346 (2013) 57-71, http://dx. doi.org/10.1016/j.chemgeo.2012.09.009.

[43] C. Le Losq, D.R. Neuville, P. Florian, G.S. Henderson, D. Massiot, The role of Al3 + on rheology and structural changes in sodium silicate and aluminosilicate glasses and melts, Geochim. Cosmochim. Acta 126 (2014) 495-517, http://dx.doi.org/10 1016/j.gca.2013.11.010.

[44] B.O. Mysen, J.D. Frantz, Raman spectroscopy of silicate melts at magmatic temperatures: $\mathrm{Na}_{2} \mathrm{O}-\mathrm{SiO}_{2}, \mathrm{~K}_{2} \mathrm{O}-\mathrm{SiO}_{2}$ and $\mathrm{Li}_{2} \mathrm{O}-\mathrm{SiO}_{2}$ binary compositions in the temperature range $25-1475^{\circ} \mathrm{C}$, Chem. Geol. 96 (1992) 321-332, http://dx.doi.org/10 1016/0009-2541(92)90062-A.

[45] W. Malfait, V. Zakaznova-Herzog, Quantitative Raman spectroscopy: speciation of Na-silicate glasses and melts, Am. Mineral. (2008).

[46] H. Maekawa, T. Maekawa, K. Kawamura, T. Yokokawa, The structural groups of alkali silicate glasses determined from ${ }^{29} \mathrm{Si}$ MAS-NMR, J. Non-Cryst. Solids 127 (1991) 53-64, http://dx.doi.org/10.1016/0022-3093(91)90400-Z.

[47] B.O. Mysen, M.J. Toplis, Structural behavior of $\mathrm{Al} 3+$ in peralkaline, metaluminous, and peraluminous silicate melts and glasses at ambient pressure, Am. Mineral. 92 (2007) 933-946, http://dx.doi.org/10.2138/am.2007.2334.

[48] A. Pasquarello, J. Sarnthein, R. Car, Dynamic structure factor of vitreous silica from first principles: comparison to neutron-inelastic-scattering experiments, Phys. Rev. B 57 (1998) 14133-14140, http://dx.doi.org/10.1103/PhysRevB.57.14133.

[49] D.R. Neuville, L. Cormier, D. Massiot, Al environment in tectosilicate and peraluminous glasses: a ${ }^{27} \mathrm{Al}$ MQ-MAS NMR, Raman, and XANES investigation, Geochim. Cosmochim. Acta 68 (2004), http://dx.doi.org/10.1016/j.gca.2004.05. 048 .

[50] A. Mekki, X-ray photoelectron spectroscopy of $\mathrm{CeO}_{2}-\mathrm{Na} 2 \mathrm{O}-\mathrm{SiO}_{2}$ glasses, J. Electron Spectros. Relat. Phenomena. 142 (2005) 75-81, http://dx.doi.org/10.1016/j. elspec. 2004.09.001.

[51] J.L. Rygel, C.G. Pantano, Synthesis and properties of cerium aluminosilicophosphate glasses, J. Non-Cryst. Solids 355 (2009) 2622-2629, http://dx.doi.org/10. 1016/j.jnoncrysol.2009.09.004.

[52] J. Alvarado-Rivera, D.A. Rodríguez-Carvajal, M.D.C. Acosta-Enríquez, M.B. Manzanares-Martínez, E. Álvarez, R. Lozada-Morales, G.C. Díaz, A. Dde Leon, M.E. Zayas, Effect of $\mathrm{CeO}_{2}$ on the glass structure of sodium germanate glasses, J. Am. Ceram. Soc. 97 (2014) 3494-3500, http://dx.doi.org/10.1111/jace.13202.

[53] A. Navrotsky, K.L. Geisinger, G.V. Gibbs, The tetrahedral framework in glasses and melts - inferences from molecular orbital calculations and implications for struc ture, thermodynamics, and physical properties, Phys. Chem. (1985) 284-298.

[54] F.A. Seifert, B.O. Mysen, D. Virgo, Three-dimensional network structure of quenched melts (glass) in the systems $\mathrm{SiO}_{2}-\mathrm{NaAlO}_{2}, \mathrm{SiO}_{2}-\mathrm{CaAl}_{2} \mathrm{O}_{4}$ and $\mathrm{SiO}_{2}-\mathrm{MgAl}_{2} \mathrm{O}_{4}$, Am. Mineral. 67 (1982) 696-717.

[55] D.R. Neuville, B.O. Mysen, Role of aluminium in the silicate network: in situ, hightemperature study of glasses and melts on the join $\mathrm{SiO}_{2}-\mathrm{NaAlO}_{2}$, Geochim. Cosmochim. Acta 60 (1996) 1727-1737, http://dx.doi.org/10.1016/00167037(96)00049-X.

[56] F.L. Galeener, Planar rings in vitreous silica, J. Non-Cryst. Solids 49 (1982), http:// dx.doi.org/10.1016/0022-3093(82)90108-9.

[57] F.L. Galeener, R.A. Barrio, E. Martinez, R.J. Elliott, Vibrational decoupling of rings in amorphous solids, Phys. Rev. Lett. 53 (1984), http://dx.doi.org/10.1103/ PhysRevLett.53.2429.

[58] D.R. Neuville, L. Cormier, D. Massiot, Al coordination and speciation in calcium 
aluminosilicate glasses: effects of composition determined by ${ }^{27} \mathrm{Al}$ MQ-MAS NMR and Raman spectroscopy, Chem. Geol. 229 (2006) 173-185, http://dx.doi.org/10. 1016/j.chemgeo.2006.01.019.

[59] D.R. Neuville, L. Cormier, V. Montouillout, D. Massiot, Local Al site distribution in aluminosilicate glasses by ${ }^{27} \mathrm{Al}$ MQMAS NMR, J. Non-Cryst. Solids 353 (2007) 180-184, http://dx.doi.org/10.1016/j.jnoncrysol.2006.09.035.

[60] D.R. Neuville, L. Cormier, V. Montouillout, P. Florian, F. Millot, J.C. Rifflet, D. Massiot, Structure of Mg- and $\mathrm{Mg} / \mathrm{Ca}$ aluminosilicate glasses: ${ }^{27} \mathrm{Al} \mathrm{NMR}$ and Raman spectroscopy investigations, Am. Mineral. 93 (2008) 1721-1731, http://dx. doi.org/10.2138/am.2008.2867.

[61] D.R. Neuville, Viscosity, structure and mixing in (Ca, Na) silicate melts, Chem. Geol. 229 (2006) 28-41, http:// dx. doi.org/10.1016/j.chemgeo.2006.01.008.

[62] J. Du, L. Kokou, J.L. Rygel, Y. Chen, C.G. Pantano, R. Woodman, J. Belcher,
Structure of cerium phosphate glasses: molecular dynamics simulation, J. Am. Ceram. Soc. 94 (2011) 2393-2401, http://dx.doi.org/10.1111/j.1551-2916.2011. 04514.x.

[63] A. Farias, M. Sandrini, J. Viana, M. Baesso, Emission tunability and local environ ment in europium-doped $\mathrm{OH}^{-}$-free calcium aluminosilicate glasses for artificial lighting applications, Mater. Chem. (2015).

[64] M.R. Cicconi, A. Veber, D. de Ligny, J. Rocherull, R. Lebullenger, F. Tessier, Chemical tunability of europium emission in phosphate glasses, J. Lumin. 183 (2017) 53-61, http://dx.doi.org/10.1016/j.jlumin.2016.11.019.

[65] R.D. Shannon, C.T. Prewitt, Revised values of effective ionic radii, Acta Crystallogr Sect. B Struct. Crystallogr. Cryst. Chem. 26 (1970) 1046-1048, http://dx.doi.org/ $10.1107 /$ S0567740870003576. 